\title{
Management of Technology: Addressing the Conceptual Premise at Issue
}

\author{
Victoria E. Erosa \\ Former Guest Professor, International Graduate Center, City University of Applied Sciences (Hochshule), Bremen, Germany \\ Email: e.rosamees@gmail.com
}

How to cite this paper: Erosa, V. E. (2020). Management of Technology: Addressing the Conceptual Premise at Issue. American Jour nal of Industrial and Business Management, 10, 1374-1429.

https://doi.org/10.4236/ajibm.2020.108092

Received: July 1, 2020

Accepted: August 21, 2020

Published: August 24, 2020

Copyright (c) 2020 by author(s) and Scientific Research Publishing Inc. This work is licensed under the Creative Commons Attribution International License (CC BY 4.0).

http://creativecommons.org/licenses/by/4.0/

\begin{abstract}
This paper's novelty come into surface by its focus on the meaning of Management of Technology, a term that reflects a specific managerial practice working at strategic, tactic and operational levels, whose theoretical foundations grants a dimension of a body of knowledge articulated in accordance to the managerial functions on which acts upon. Featuring a complex system of research methods articulated in accordance to the nature of the research' interest, Management of Technology construct (MOT) come into view as a single conceptual unit. Results presented here include MOT structural management functions' boundaries setting, the modelling of the Nomological Net in which the construct is implanted, and the interconnections with its observable operational techniques and practices. The paper's content contributes to gain understanding on the configuration of the theoretical net that gives to the Management of Technology construct its structural dimension, identified as the managerial essential functions that made the abstract idea visible through its observable practices.
\end{abstract}

\section{Keywords}

Technology and Economics, Management of Technology, MOT Nomological Net, MOT Theory Building, Management of Technology Construct

\section{Introduction}

The idea to work on the meaningfulness of an abstract concept or construct seems to be appealing enough as to open the discussion by means of an exploration on the matter. Management of Technology view under these lens moves the analysis into the rich theoretical components that supports the complex-abstract concept termed in this paper the Management of Technology (MOT hereafter) Construct. The turn into this view grants research efforts to address a theoretical 
concept that seems to be of paramount interest for analysis as the importance of the MOT academic discipline venue gains wider space in business and engineering sort of educational programs operating to cover professionals' demand, alongside a growing presence in related literature wherein multiple interpretations of the term frequently emerge.

To a great extent, support to the initiative to explore MOT construct' theoretical configuration is rooted in a collective of thinking from diverse strands of knowledge that deal with the notion of mental content or representation of an idea in a certain way-phrases that express a meaning - as suggested by few reflection questions on the matter like: What are persons thinking when referring to Management of Technology? What persons think in regard of this term is the same for everyone? Is the term assumed to be clear enough for everyone? What is meant when such a concept as Management of Technology is under the spotlight? A quick response could lead to misplace the core idea or to dilute the relevance of the question by moving the focus into the specifications of the persons' segmentation: what does the term means to Students? Scholars? Academicians? Practitioners? In Business or Engineering fields? and so on. In contrast, giving deepest reflection to the issue risen by those questions, a Philosophy view would take the analysis into the think of or about something arena, referred to as a mental representation (Russell, 1905; Kaplan, 1972; Mendelsohn, 2004), being this idea found as well in the domains of the Descriptive Psychology, within the Phenomenology area, identified by its concern on the essential structures of cognition from the first-person view and their relations with the things known (Brentano, 1995). This interpretation leads to consider as the central structure of an experience the notion of Intentionality related to the approach or reference to a content, meaning or course of mind to things, state of affairs, events, etc. referring to the mental content or representing something to be a certain way (Husserl, 2001).

Beyond the strong awareness of the relevance of such a theoretical referential frame, significant in its own right and recognized as fundamental to be reviewed, being the references introduced sufficiently into the research scenario these grounds of the topic are kept out of the scope of the present analysis whose attention is centered in the MOT Construct configuration as the abstraction that fits the representation of this novel fast-developing branch of knowledge. The purpose to introduce this reasoning is to underline why come into view the importance of the construct' configuration topic for the MOT research agenda. The figure of a Theoretical Referential Frame articulated in Diagram 1-to put in view the interaction among the ideas exposed-is selected as the proper device to take into the limelight the interest to explore the meaningfulness-what it is for something to be meaningful to someone (O'Rourke, 2005)—of the MOT Construct in theoretical, abstract terms, in conditions of other theoretically related constructs, as works for the exploration about how its Nomological Net structure is configured. 
The theoretical referent presented in Figure 1 intends to reinforce clarity in the reasons why the selected research topic can give reasonable insight into the meaningfulness of MOT construct. The caution to be observed is that the point at issue here is to explore the theoretical construct stated in the main title of this paper as Management of Technology, referred to as the Concept-ideas that represent general categories or types of things (collinsdictionary)-under the light of the ideas or theories on which is based namely Premise, understood as an idea or theory on which a statement or action is based (dictionary. cambridge). Following this Logic-based explanation (Hardegree, 2009), and being found consistency with the Semantics' compositionality principle which holds that the meaning of expressions is a function of their component's meaning (Moore, 1989), it is established that this research gives prominence to the MOT construct structural configuration, focusing the attention on its theoretical, abstract meaning, in conditions of other theoretically related constructs in clear reference to be engage in the exploration of the construct's Nomological Net as conceived in the Social Relations Research Methodology (Cronbach \& Meehl, 1955; Judd, Smith, \& Kiddler, 1991) being acknowledged that... Learning more about a theoretical construct is a matter of elaborating the nomological network in which it occurs, or of increasing the definiteness of the components... (Cronbach \& Meehl, 1955). Thus, the research interest is operationalized through the following Research Question... How is MOT Nomological Net' Structure configured? Establishing so a clear difference with the construct validation stage by focusing first, on the required input modelling step.

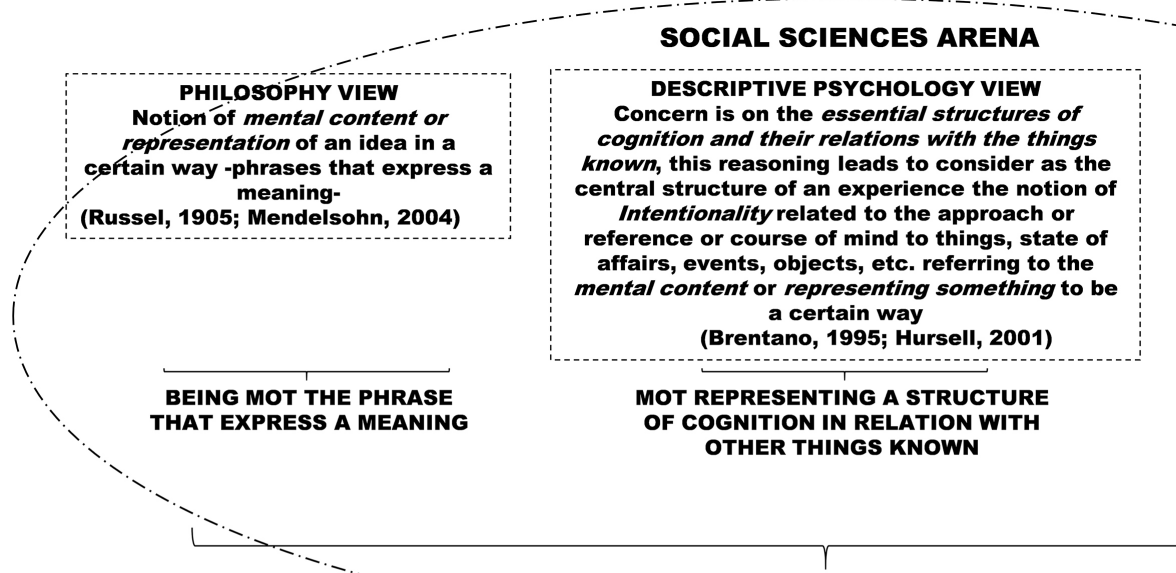

THE MOT PHRASE EXPRESS THFE-MEANING OF .... A STRUCTURE OF COGNITION IN RELATION TO ....THE. IDEAS OR THEORIES ON WHICH

$$
\text { THE CONCEPT IS BASED }
$$

Explore MOт' conceptual premise in theoretical, abstract terms, in conditions of other theoretically related constructs, as means to gain in understanding upon its configuration identified by its Nomological Net

BENEFIT MOT CONSTRUCT' VALIDITY

SUPPORT EMPIRICAL MEASUREMENTS OPERATIONS AND PROCEDURES DEFINITIONS (OPERATIONAL DEFINITIONS)

Notes to benefit clarity:

a) Social Sciences in this time-period include as key disciplines psychology, sociology, linguistics and economics. https://www.britannica.com/topic/social-science

b) The study of Logic is identified as one of five main branches of Philosophy. http://philosophy-index.com/philosophy/branches/

Source: Diagram structured upon the basis of information retrieved from reference-listed sources

Figure 1. Theoretical Referent Frame of the research interest in regard to MOT' Construct configuration. 
The question of how the Management of Technology (MOT) construct is configured has not yet, admittedly, received the attention that deserves in the literature on the theme, mainly dominated by the analysis of the application of a wide array of techniques to a certain number of phases or stages of a managerial process in which the main focus-view is Technology as a productive or as a competitive resource. Moving away from the enormous weight of discourse around technology benefits-consequences-best practices-impact and other implications of practical business-nature prevailing during about half Century, registered in a profuse collection of very well documented articles, papers and books, special consideration is given here to the theoretical support of the Management of Technology construct as it is recognized at present when denoting to a key transversal evolving discipline that changes business and engineering professional market profiles, education curricula and decision-makers' mindset by providing a toolkit to deal with the challenges set in motion by the dynamics of Technology Innovation and its subsequent Technological Change.

In this state of things, it is point up that this paper addresses itself to explore MOT' Nomological Net-embedded set of theoretical constructs and their relationships, stated at theoretical level (Cronbach \& Meehl, 1955; Judd et al., 1991) - intending to improve the understanding of the MOT construct' structural configuration, upon the basic acceptance that understanding requires meaning.

\section{Management of Technology. The Construct' Theoretical Milieu}

Being aware that essential to the purpose of the analysis is the idea that the main components involved in the research interest-Management and Technology-should not be analyzed in isolation from the other due to the fundamental characteristic of being unite into a different item (MOT), yet it is recognized that it becomes to be necessary here that each one of them should be previously reviewed independently as an initial step of an analytical procedure followed to support throughout the study the Nomological Net exploration. This step refers to the paradigm setting in which the research design and analytical approach would be framed to best answer the research question of interest (Denzin \& Lincoln, 2003). Recognizing that MOT techniques, processes and activities emerge striving to support, enable, drive and/or create business profit or benefits, the Economic Paradigm is identified as the suitable one to examine the research interest determined. The revision of systems of thought and knowledge-called epistemes or discursive formations (Foucault, 1969)-apropos the relation between Technology and Economics is set forth in this section in order to frame the reasoning sequence that supports MOT' core components. Justified in terms of the research' internal logic pursue, thematic arrangements of the information handled are built on upon the basis of preserving the context of sources of different discipline origin by creating separate groups of knowledge under the the- 
matic criteria, adopting so the view from the provenance principle of the archival research field, regarded to be appropriate as here information is collected with the purpose of examination from sources in text already existing (Pearce-Moses, 2005).

\subsection{To Gain Understanding in the View of Technology as a Major Transformation Driver: An Insight}

Early $19^{\text {th }}$ Century perception in regard to the benefit of the use of technology innovation with practical business purposes is illustrated by the following statement printed by The Times in its November 29, 1814 issue: "Our Journal of this day presents to the public the practical result of the greatest improvement connected with printing, since the discovery of the art itself.." (historyofinformation. 4491). The greatest improvement refers to the introduction of Friedrich Koening' development of a new steam-driven cylinder press that surpasses four times the velocity of the hand operated process, producing per-hour an initial output of 1100 printed sheets (historyofinformation. 4613). The example' early $21^{\text {st }}$ Century interpretation is likely to be expressed in a different tone, setting the content in the context of a given firm' strategic kind of meeting... Aligned to the firm's long term strategic objectives enters into production phase a Technology-based innovation investment with the purpose to increase the firm' competitiveness and enhance profit creation... In such a contemporary context, this might be considered as an annual-basis project derived from the firm's longterm strategy implementation phase, to be managed through the firm's ERP, assigned with a programmed budget to a given operational area. The two Centuries' span of thought is condensed in today's activities regarding Technology consequences and determinants either at firm level as at economy' aggregate level. The admittance of Technology into the Economics sphere speaks volumes in recognition of the relevance of this variable in such a solid field of knowledge, being for that reason a source of ideas of key interest when the focus of attention is MOT' construct.

Technology evolution history, also referred to as technical progress historiography within History' Research arena (Rosenberg, 1982), provides support to sketch a general description of the type of theoretical environment, milieu, that gave place to the emergence of the Management of Technology term, being the complexity and extension of the historical perspective widely recognized in the Economic History area of knowledge as helpful tool to have some light upon the emergence of reasons for technology to be managed as a concrete operational practice working under its own set of principles, processes, techniques and interaction rules either at macro as at microeconomic level. The primary interestfitting in the consequences of technological change analysis perspective-is to introduce insights on Technology view as major transformation driver as well as a fundamental block for innovation efforts and efficiency means for industry, which are identified since late $18^{\text {th }}$ Century due to the beginning of economic 
and social changes fostered by the Industrial Revolution which took place during that time period, propelling the transition to new kind of manufacturing processes enabled by steam-fueled machines and related techniques. The impact of such new paradigm became visible by means of the transformation of the social profile from an agrarian-rural society into an urban-industrialized one.

Grounds of the importance of Technology in economic growth and development processes are found in the domain of the Classic Economic Theory, based on the works of Adam Smith, David Ricardo and John Stuart Mill (Kerr, 1993), developed at the heart of the context that will lead to the emergence of the economic system termed industrial capitalism (Encyclopedia of Marxism at Marxism.org; Marx, 1867). In such context is recognized as an utmost concept the association of capital accumulation-as investment creation means-and technical change as considered in the principles of Smith' division of labor and Ricardo' changes in methods of production (Kerr, 1993).

Set at such scenario frequently nurtured by political economy theories, the technology issue enters into the $19^{\text {th }}$ Century' industrialization momentum as a core component of the notion of Modes of Production-distinctive ways of production-whose private ownership effects in capital creation determined the nature of a full economic system referred to as Capitalism, being extensively explained in and by the Marxist Theory (Marx, 1867). Upon the idea that part of the Capital is wealth in productive use represented by all man-made means of production, is then reasonable to consider technology to be a Factor of Production as a component of the Capital item that integrates the trilogy of Factors of Production along with Land and Labor. In such theoretical field where Factors of Production and Economics are the foci of attention, investment or Capital Formation is at the core of requirements to increase an economy' production capacity. This perspective moves the analytical view into the technology determinants side. A call of attention is made here to consider the context at the point of time in which the theory is stated, as a main condition to understand the view of Capital as a passive factor of production that to be productive requires a Labor' actionable platform, the theme' in-depth revision is beyond the boundaries of this research' interest.

As the analysis on the topic evolves, after being established the idea of Technology as a core component within one of the factors of production termed Capital operating at Economy level, a recognized landmark that changes the way in which macroeconomics comes near to the microeconomics perspective, enters into the screen. The Theory of Production is developed in early $20^{\text {th }}$ Century given attention to the recognized concept of factors of production mix by focusing the interest in how to use them to obtain their highest benefit (Cobb \& Douglas, 1928).

How and how much to use? The implications of these queries bridge technology view into the microeconomic industry/firm sphere focusing in the group of inputs required to fulfill the production goals. The instrumental means to repre- 
sent the relation between two or more inputs amount-usually Labor and Capital being a measure of technology and assets investment-and the resulting output produced, is known as the Cobb-Douglas production function. In the modern era, its view focused on an entire economy has been discussed by some economists upon the light of aggregate production role in economic theory (Temple, 2006). Within this theoretical strand, an important differential line for technology setting is later pointed by Wolman (1921)... Production may, from one angle, be considered as a synthesis of the contributions of managers, workers, and inventors. It is the function of political economy to be aware of these contributions, to know the conditions under which such contributions are advantageously made and the conditions under which they wither. Competent description of this type of knowledge can be accomplished only through the medium of a relevant terminology...

At mid-20 $0^{\text {th }}$ Century, economists' interest turns to a closer look into the relation between the Production Function and the Capital, framing the analysis in the investment slash profit generation line of reasoning, integrating so the determinant view of technology change-investment-with the consequences view in the figure of profit. From this fundamental theoretical venue, Robinson (1953) notions regarding... the amount of capital embodied in a stock of equipment is the sum of the supply prices of the plants of which is composed... follows the classical view of Technology as a Capital representation by means of investment stating... Investment in new equipment is not made unless its gross earnings (excess of output over wages bill in terms of output) are expected to be sufficient to amortize the investment over its working life... This idea is moved forward profiling further basis to be integrated into the innovations-cost considerations as well as in its role as efficiency source and profit maker... the cost of capital includes the cost of capital goods, and since they must be constructed before they can be used, part of the cost of capital goods is interest over the period of time between the moment when work was done in constructing capital goods and the time when they are producing a stream of output (Robinson, 1953)... For this research interest, a third contribution of this theoretical frame is identified to be an intangible feature identified at the operational environment, termed by Robinson as the state of technical knowledge explained as the... set of techniques which could be used, with a given amount of current labour, to produce a flow of output of the commodity concerned, while maintaining the productive equipment required intact (Robinson, 1953)...

The importance of Robinson's quotes to this research' purpose come into sight by the analysis of the relation of technology and capital that supports the view of technology as an investment to be recovered by way of profit generation, notion that seems to coexist with the accepted sociology grounded view of technology' primarily role as means to fulfill human needs. These two ideas seem to provide solid reasons for the emergence of a Management of Technology operational field. The relation of Technology and Economics is found as well in the 
regional development/growth theoretical branch. The view of Technology from the concerns of the body of classical Economics and Production Theories also brought to the fore the key subject matter of invention and innovation' position in the firms benefit, giving place to the systematic statement of the expected positive impact of innovation over economic development as well as a source of competitiveness and profit growth, as is reflected on Kuznets' remark as a distinct characteristic of modern industrial societies their success in applying systematized knowledge-derived from scientific research-to the economic field (Kuznets, 1966).

At this stage of analysis is identified a Macroeconomics meets Microeconomics point related to technology influence implying two venues: innovation and technology-based manufacturing slash operational activities. Evidence of the interest in the invention/innovation notions since the $19^{\text {th }}$ Century is exemplified by Tarde's classical works which develops ideas on imitation, considered as a basic social-phenomena in which the presence of a previous invention or innovation is recognized (Tarde, 1895; Tarde, 1903). Such a complex theoretical bridge is a matter of attention, from the economy lenses, by Schumpeter close to mid- $20^{\text {th }}$ Century who became afterwards the referential source of economic studies on innovation and derived themes (Schumpeter, 1939). Among the ideas introduced, highlights the notion of a discontinuous-disruptive-change that takes economy from a static mode to a dynamic course, being expressed later in terms of the description of development as a structural-changes' historical process basically driven by innovation, in whose absence a negative effect on the marginal productivity of production factors is expected (Schumpeter, 1942). In the macroeconomics front, a close relation between manufacturing production-technology based activity-growth rate and the GDP (Gross National Product) is considered in Kaldor's Cumulative Causation Model (CCM) adding up so a contribution to frame the relevance of technology on economic growth (Kaldor, 1966).

At present time, influences of Technology over the Economy are incorporated into World Bank' development indicators as Gross Capital Formation, also known as capital accumulation, the concept refers to reinvestments-additions to the fixed assets of the economy plus net inventories-into capital assets (World Bank, 2016). A condensed revision of Regional Development theories supporting the key role of manufacturing industry and/or innovation on economic growth is found framing recent analysis centered on the Technology Culture theme (Erosa, 2012).

\subsection{Innovation Branches off}

The body of thought analyzed so far grants sufficient support to understand the reasons behind the emergence of a tacit paradigm of chains of causation running from science to economic life, positioning technology innovation as the central feature of competitiveness at firm level and of economic growth at economy' ag- 
gregate level. As innovation develops its own knowledge track, terms such as Research and Development, Basic and Applied Science and Experimental Development made a disrupting appearance as technology-based innovation' source of origin involving the productive sectors, academy and an emergent kind of organization identified as research and development (R\&D) firms and/or institutions focused on specific fields of interest. The output of such intensive capital-consuming activities is expected to be the golden nugget in terms of new products, components, knowledge/know-how, efficient processes, tangible assets or any given source of an expected competitive advantage set at the market' batthe field. Economic thought on the matter is condensed in Robinson' statement... The effect of inventions, unless they are highly unfavorable to capital in a technical sense, is to raise the rate of profit obtainable by a given amount of capital, and to increase its relative share in output (Robinson, 1953)... It seems that the next issue to address is innovation' theoretical concept as Technology' embryonic phase being a necessary component of the theoretical frame that supports along this analysis: 1) the view of technology innovation as a long-term investment process to be recovered over time throughout a legal platform of Intellectual Rights figures ownership visible in a derived typology of tangible and intangible assets, 2) the view of technology innovation as R\&D investment and founding activities' output, and 3) the introduction into the economic variables of R\&D components as investment measures and economic indicators. The reason behind the attention to these aspects of technology innovation as fitting components of this research' purpose, is that at the core of them resides a standardized and widely accepted basis for Technology definition.

Innovation as a theoretical concept has been a concern of a variety of scientific fields focusing mainly on the diffusion process. In this referent' sphere, it is observed that the word Technology does not appear, which suggests that the relation between innovation and technology is taken for granted or in any case is applied indistinctly to technology-based innovation, technology development and terms of the kind grouped under the generic label of technology innovation. In the economic domain, during the second half of the $20^{\text {th }}$ Century, Mansfield (1968) introduced a modern interpretation considering innovation as a four dimensions process having each of them a conceptual referent that determines a sequence running from the idea to the full immersion into the economic flow:

1) invention-understood as... the process of contriving and producing something not previously known or existing, by the exercise of independent investigation or experiment (thelawdictionary.org)... possible to be carried out without commercialization purposes;

2) innovation-defined as a function that combines productive factors in new ways covering either a new commodity, a new form of organization or new market creation, carried out to be introduced with a commercial purpose into the economic arena (Schumpeter, 1942) being fulfilled this function by a social agent named entrepreneur, in short, a process that goes from the new-idea to 
market introduction;

3) diffusion refers to the process by which innovations are adopted/not by their potential users, being its importance recognized in theoretical works from anthropology, sociology and industrial environment (Godin, 2014), lately widely accepted as a core component of marketing strategies in consistency a key idea shines out from Tarde's statement (Tarde, 1895)... every invention or discovery tends to expands-propagate-reproduce in its social environment...;

4) imitation-understood as the action of using something as a model or to copy something (lexico.com), (Djellal \& Gallouj, 2014)—is the stage in which the profit potential of a new product/process/market/production methods/business organization is spotted by investors willing to benefit from innovation of the kind. A continuity of the diffusion phase is also known as the contagion by imitation. This view anchors the topic in the Sociology field of study.

The string of ideas articulated in Mansfield' innovation process attracted huge amounts of interest, centering diffusion phase as the linking echelon that precedes the introduction to the economic flow, thus, creating a space for the emergence of influential conceptual advances on the matter as found in Beal' (1957) five diffusion stages of awareness-interest-evaluation-trial-adoption, the introduction to the horizontal diffusion model by Leonard-Barton \& Rogers (1981), the consequences of innovation on the management of change studied by Leonard-Barton (1982), the contributions of Rogers (1983) concerning innovation diffusion and the classic Bass' (1969) Diffusion of Innovation Model, widely used to forecast new products' introduction/adoption. Bass' mathematical model-also known as the Bass equation-provides the operational means to an S-shape curve graphical representation of the diffusion process stages, whereas Vernon's (1966) application of the idea to a new technology product introduction in the international trade field extends Product Life Cycle (PLC) body of theory established in early $20^{\text {th }}$ Century' second half.

Rooted in the marketing field, an explanation of the PLC concept is provided by Levitt' (1965) statement... The life story of most successful products is a history of their passing through certain recognizable stages. These are Stage 1 market development, Stage 2 market growth, Stage 3 market maturity and Stage 4 market decline... Such a powerful concept is expressed in a diagram by a bellshaped curve-later represented by Cox Jr. (1967) using an equation-divided into four segments referred to as each of the mentioned stage, and revised as a construct (Polli \& Cook, 1969). Grounded on this theoretical basis, a collection of adaptations of PLC emerge since, introducing other phases or renaming them to suit into areas outside the marketing studies circle. Product Life Cycle Theory, paved the road for some insights' expansion into the Technology field evolving into a model referred to as Technology Life Cycle (TLC), the technology/innovation S-curve, the Technology diffusion model and similar terms, with common acceptance to identify technology adoption patterns as well as technology evolution' trends. Set on this environment, assuming that the innovation stimulus rise from market promises or threats, the basic Levitt's four stages of PLC re- 
ferred to as introduction-growth-maturity-decline evolves into the TLC model which includes R\&D stage-called pioneering in the marketing field-configuring then a five stages process- $\mathrm{R} \& \mathrm{D}$, introduction, ascent, maturity and declinebeing innovation found as result of the first stage that takes care of all the aspects related to technology' embryonic phase that runs from the idea emergence/identification to the commercialization in the economic flow.

For the purpose of this research here is a fundamental line to draw up indicating the boundaries between the $\mathrm{R} \& \mathrm{D}$-derived-technology-innovation stage management arena and the action field of MOT positioned at the starting point of technology commercialization-introduction-launching, maturity and decline, in either technology supply side-producing technology for the market-demand side-acquiring technology from the market-strategic side-technology as a business model, aligning technology to the business strategic objectives within macroeconomic policies and regulations frame-and the operational side enabling efficiency and supporting business networking practices by means of investment-based technology solutions. This is the point to reiterate that the focus of the present research follows the TLC view as it comprises the coexisting notions of a chain of innovation causation running either ways from economic life to Science as well as from Science to economic life. Being innovation not regarded as the unit of analysis of this study, further extended analysis on the topic is out of its scope, references on the matter will appear as required background further on.

\subsection{Technology as an Umbrella Term}

Given the importance of terminology, attention is required to identify the differences existing among the terms Technology, Research and Development (R\&D), Scientific and Technological Activities (STA), Experimental Development, Innovation and words of the kind that became a specific language in the context analyzed. It is worthy to note that-moving forward from its Greek roots Techne = skills, craft, art and Logos $=$ the systematic study of... (etymonline.com) -the term Technology has gone through a number of definitions being found in a 1895 dictionary entry the word referring to... That branch of knowledge which deals with the various industrial arts, the science or systematic knowledge of the industrial arts as spinning, metal working or brewing (Whitney, 1895). By mid$20^{\text {th }}$ Century the term gained common acceptance as a generic term used as referent of physical devices such as equipment and machinery including parts, components and know-how being applied indistinctively with the technical designation. Definitions presented in Table 1 provide an example of the differences found in regard to the word Technology registered as a noun-a word that functions as the main or only element of subjects, often names a thing, person, idea or place (Webster, 1989) - in a variety of Dictionary entries, including the largely adopted sources that emerged in the Digital Era which gained preference mainly among the Millennium generation. 
Table 1. Technology. dictionary definitions. Noun.

\begin{tabular}{|c|c|c|c|c|}
\hline Collins Dictionary & Oxford Dictionary & Webster's Dictionary & Google & Wilkipedia \\
\hline $\begin{array}{l}\text { Technology refers to } \\
\text { methods, systems and } \\
\text { devices which are the result } \\
\text { of scientific knowledge } \\
\text { being used for practical } \\
\text { purposes. (Variable noun) }\end{array}$ & $\begin{array}{l}\text { Scientific knowledge } \\
\text { used in practical way, } \\
\text { for example in designing } \\
\text { new machines. (Noun) }\end{array}$ & $\begin{array}{l}\text { 1) Knowledge that deals } \\
\text { with industrial arts, applied } \\
\text { science, engineering, etc. } \\
\text { 2) The terminology for art, } \\
\text { science, etc.; technical } \\
\text { nomenclature. } \\
\text { 3) A technological process, } \\
\text { invention, method or } \\
\text { the like. } \\
\text { 4) The sum of the ways in } \\
\text { which a social group provide } \\
\text { themselves with the material } \\
\text { objects of their civilization. }\end{array}$ & $\begin{array}{l}\text { The application of } \\
\text { scientific knowledge } \\
\text { for practical purposes, } \\
\text { especially in industry. } \\
\text { Machinery and equipment } \\
\text { developed from the } \\
\text { application of scientific } \\
\text { knowledge. } \\
\text { The branch of knowledge } \\
\text { dealing with engineering } \\
\text { or applied sciences. }\end{array}$ & $\begin{array}{l}\text { Technology ("science } \\
\text { of craft") Is the sum of } \\
\text { techniques, skills, methods } \\
\text { and processes used in the } \\
\text { production of goods or } \\
\text { services or in the } \\
\text { accomplishment of } \\
\text { objectives such as scientific } \\
\text { investigation. Technology } \\
\text { can be the knowledge of } \\
\text { techniques, processes, } \\
\text { and the like or it can be } \\
\text { embedded in machines } \\
\text { to allow for operation } \\
\text { without detailed knowledge } \\
\text { of their workings. }\end{array}$ \\
\hline
\end{tabular}

Source: Table structured upon the basis of information retrieved from Dictionary' reference-listed sources collinsdictionary.com oxford learners dictionaries Webster 1989: 1458 Google.com/search?en.wikipedia.org.

From the sample revised, four out of five definitions include the notion of... scientific knowledge applied/used for practical purposes... making two of them reference to the physical devices that represent and to techniques, methods, skills and processes used in production. This comparison discloses noticeable differences encompassing a common acceptance of Technology as a resulting application of scientific knowledge that deals basically with engineering or applied sciences. Clearly even when informative, the literal use of the definitions of Table 1 seems a risky thought as are far to suit the spirit of the Management of Technology field of knowledge, being for that reason unlikely to apply any of them when referring to, for example, the rationale of a MOT educational program as the same as... management of machinery and equipment developed from the application of scientific knowledge (technology) ... or to describe in the context of a job position, MOT' professional competences as those applied to an open and general statement of the type of... management of scientific knowledge used in practical way... This condensed revision of the term suggests that to be articulated as a fitting component into the MOT construct, technology conceptualization comprise a number of theory-based building blocks as upheld by the Factors of Production/Capital perspective as well as by the Resource View theoretical sphere-revised previously-to be completed by introducing the Management component and its derived operational venue set on the field of technology use and usage at individual level.

\subsubsection{Key Sources' Evolving Trajectory}

As the term' definition seems to remain elusive, an immersion through successive layers of materials-dealing with related definitions, measurement and indicators determination-follows as organized effort to untangle the skein, taking 
the analysis forward into the measurement field of action. The course of these activities is set in consistency with the view that requires a necessary frame to build up standardized World Wide statistics on economic variables to input policy-makers engaged on Science and \&Technology planning activities, as dictated by the nature of the chain of causation established from Science to economic life. Since R\&D activities are regarded as an indicator of attainment of a major milestone in economic development, is considered appropriate to introduce at this point a brief revision of the definitions of technology-related activities on this matter, as the closure of the Technology term revision.

In this context, intense activity for R\&D measurement has been conducted by the Organization of Economic Development (OECD) as well as by UNESCO being, in the more than a 60 years period trajectory of activities, interaction points between both institutions. For the purpose of the present analysis, the reference to the sources is of most importance interest due to three reasons. The first reason relates to the role of Scientific and Technical Activities (SAT) comprised on Scientific Research and Experimental Development (R\&D) that requires to be identified by its specific register within the countries' National Account System (NAS) with a standardized measurement system built upon reliable indicators. This view put emphasis on the notion of Management of Technology activities set at the Macroeconomics level within both production and education sectors, operating through a set of key performance indicators that inputs development planning and policy making activities. The second reason is found in the conceptualization of Technology at its earliest or embryonic lifecycle stage-R\&D—given the dominant logic of the measurement defined by a sequence/continuum as Fundamental Science-Applied Science-Experimental Development, in which resulting innovation is from that point taken into its own specific measurement track. The third reason rise from the observation that the relevance of these quotes turns visible as the essence of their definitions, regarding Applied Science and/or Experimental Development, seems to permeate the dictionary' entry that discloses likeness of content in the form of a variety of broad Technology conceptual definitions, as the ones previously illustrated.

To grant clarity to the timeline and interaction of OECD and UNESCO wideranging works on the topic, a visual representation of the activities' trajectory is depicted in Figure 2. In its upper side two venues of work are traced, identifying in the first-starting in early $1960^{\prime}$-attempts to standardize information from Research and Development Activities (RD) when a Proposed Standard Practice for Surveys on Research and Development was analyzed and agreed for a common approach to measure and report RD statistics among country members of the Organization for Economic Cooperation and Development (OECD), in an expert' meeting held in Frascati, Italy (June, 1963), setting the foundations for a document labelled since then as Frascati Manual that later on became the World standard for S\&T activities measurement (OECD, 1963). The manual addressed $\mathrm{RD}$ dynamics pace through several revisions published in seven editions so far 


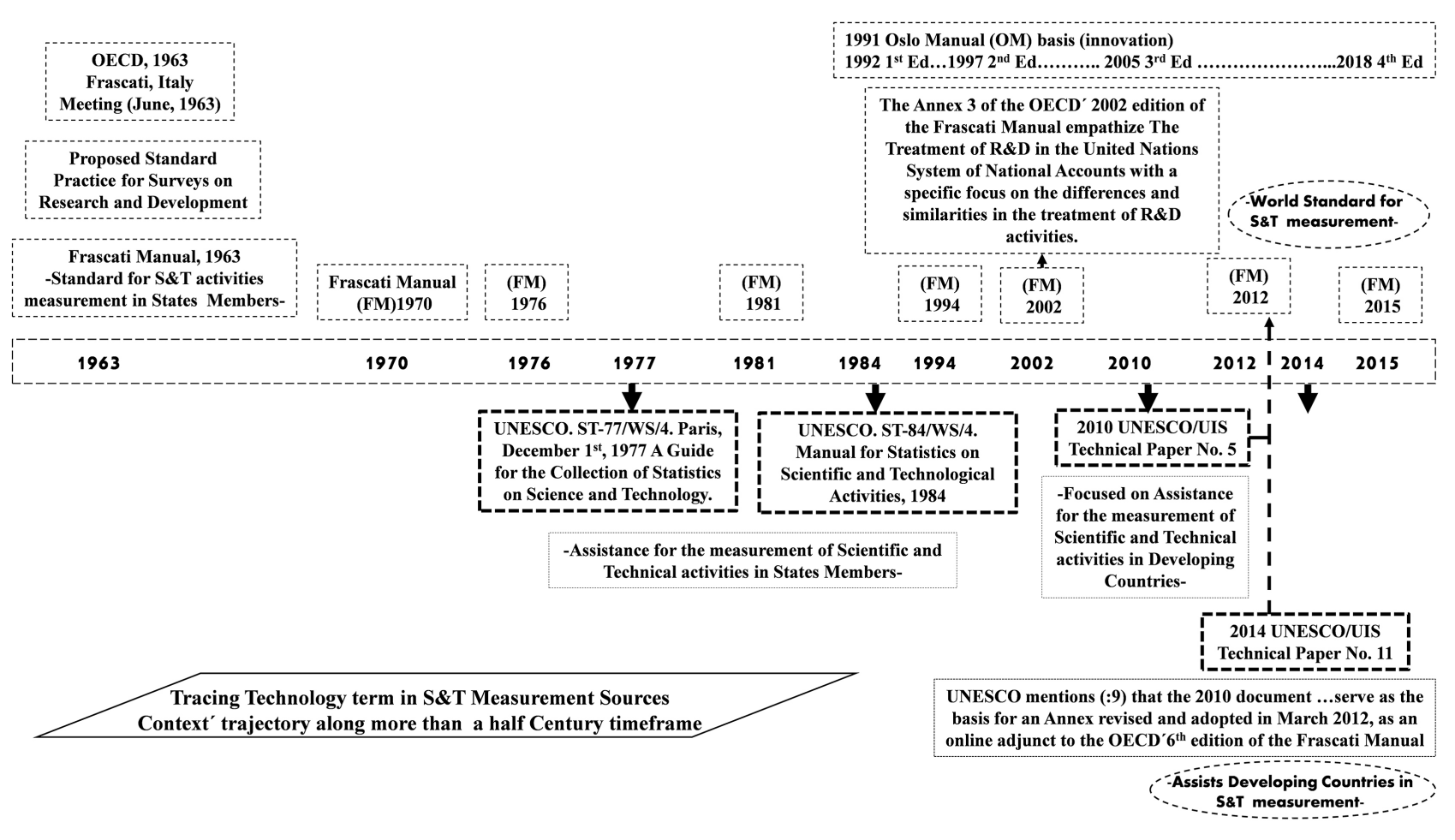

Figure 2. Tracing technology term. S\&T measurement sources timeframe.

(1963, 1970, 1976, 1981, 1994, 2002 and 2015), being stressed in the Annex 3 of its 2002 edition (OECD, 2002)... The Treatment of $R \& D$ in the United Nations System of National Accounts (SNA)... with a specific focus on the differences and similarities in the treatment of $\mathrm{R} \& \mathrm{D}$ activities, declaring in this regard that... The SNA is concerned with economic activities. The first question that must be answered, therefore, is what constitutes an economic activity, since this determines what falls within the scope of the national accounting system and thus enters gross domestic product (GDP). There is no difficulty in defining as economic those activities that result in the production of goods and services for sale on the market. $R \& D$ is generally an economic activity as defined above (OECD, 2002).

The second venue traced in the upper right side of Figure 2 is centered in the innovation track component. Works on the matter begin in 1991 leading to publish in 1992-by OECD and Eurostat-the $1^{\text {st }}$ edition of the document known as the Oslo Manual under-titled... a guideline for collecting, reporting and using data on innovation... (OECD, 1992) opening with this action a new venue for a separate treatment for innovation related measures and indicators creation, concentrating the S\&T related topic in the Frascati Manual. The Oslo Manual has gone into various revision since, being its $4^{\text {th }}$ edition (2018) released in October 2019 the one that includes a detailed explanation of an updated innovation concept (OECD, 2018) as well as a general definition (OECD, 2018)... An innovation is a new or improve product or process (or combination thereof) that differs significantly from the unit's previous products or processes and that has 
been made available to potential users (product) or bought into use by the unit (process).

The lower side of Figure 2 gives attention to the topic on the grounds of education given by UNESCO first identified in 1977 release-marked as limited distribution-of... A Guide for the Collection of Statistics on Science and Technology... (UNESCO, 1977), to be used as assistance for the measurement of Scientific and Technical activities in States Members. The document evolved to the 1984 Manual for Statistics on Scientific and Technological Activities ST-84/ WS/4 (UNESCO, 1984). Moving forward on the topic, activities undertook during 2006-2009 lead to the publication in 2010 of UNESCO/UIS Technical Paper No. 5 focused on the assistance for $R \& D$ measurement in developing countries (UNESCO/UIS, 2010). Years later, in UNESCO PAPER 11 (UNESCO/UIS, 2014), is mentioned that the referred UNESCO' 2010 document... serve as the basis for an Annex revised and adopted in March 2012, as an online adjunct to the $20126^{\text {th }}$ edition of the Frascati Manual... In its seventh version of 2015, the OECD' Frascati Manual (OECD, 2015) recognizes that its international guidelines are followed by all countries as World Standard, while UNESCO/UIS Technical Paper 11 provides assistance to countries at early stage of R\&D measurement.

Operationalizing the agreement, the Institute of Statistics (UIS) of UNESCO provides on annual basis a R\&D data collection questionnaire to countries not covered by data collection of other partner organizations (OECD, Eurostat/Statistical Office of the European Union) and the Inter-American and Ibero American Network on Science and Technology Indicators (RICYT).

The brief narrative of the R\&D and ST activities' whereabouts is essential to understand the magnitude of the importance of Technology in the economic flow' dynamics.

\subsubsection{The Emergent Definitions}

Being consistent to the nature of their origin, these intensive-extensive-long term activities focused the interest on definitions of the concepts whose performance is to be quantified using numerical information-measures-and their derived series of indicators. Based on results of a general analysis of the documents referred, inputs form Table 2 correspond to OECD Frascati Manual $7^{\text {th }}$ edition (2015) as contains the World standards for R\&D measurement, and to UNESCO (1977) for being the document released as their first source of definitions whose spirit remains, although is recognized that... $R \& D$ has been defined and measured in harmonized ways for more than 50 years and $R \& D$ statistics are widely used for policy-making and analysis in both advanced and developing countries... (UNESCO/UIS, 2014; OECD, 2015).

In this environment, a first distinction is to be made between the names and categories assigned to R\&D activities by each source to prevent confusion or misinterpretation by interchanging their use. The OECD sources apply the R\&D term as generic referent comprising three types of activities: basic research, 
Table 2. Technology. R\&D activities' conceptualization.

\begin{tabular}{|c|c|c|c|c|}
\hline SOURCE & $\begin{array}{l}\text { (R\&D) Research and } \\
\text { experimental development }\end{array}$ & Basic Research & Applied Research & $\begin{array}{l}\text { Experimental } \\
\text { Development }\end{array}$ \\
\hline $\begin{array}{c}\text { OECD, } 2015 \\
\text { Frascati Manual, } \\
2015 \text { Chapter } 2 .: 44 \\
\text { R\&D covers three } \\
\text { types of activity: } \\
\text { basic research, applied } \\
\text { research and experimental } \\
\text { development }\end{array}$ & $\begin{array}{l}\text { Comprise creative and } \\
\text { systematic work undertaken } \\
\text { in order to increase the } \\
\text { stock of knowledge- } \\
\text { including knowledge of } \\
\text { humankind, culture and } \\
\text { society-and to devise } \\
\text { new applications of } \\
\text { available knowledge. }\end{array}$ & $\begin{array}{l}\text { Is experimental or } \\
\text { theoretical work } \\
\text { undertaken primarily to } \\
\text { acquire new knowledge } \\
\text { of the underlying } \\
\text { foundations of phenomena } \\
\text { and observable facts, } \\
\text { without any particular } \\
\text { application or use in view. }\end{array}$ & $\begin{array}{l}\text { Is original investigation } \\
\text { undertaken in order to } \\
\text { acquire new knowledge. } \\
\text { It is, however, directed } \\
\text { primarily towards a } \\
\text { specific, practical aim } \\
\text { or objective. }\end{array}$ & $\begin{array}{l}\text { Is systematic work, drawing } \\
\text { on knowledge gained } \\
\text { from research and practical } \\
\text { experience and producing } \\
\text { additional knowledge, } \\
\text { which is directed to } \\
\text { producing new products } \\
\text { or processes or to } \\
\text { improving existing } \\
\text { products or processes. }\end{array}$ \\
\hline $\begin{array}{l}\text { UNESCO, } 1977 \\
\text { Scientific and } \\
\text { Technological } \\
\text { Activities (STA) }\end{array}$ & $\begin{array}{l}\text { A. Scientific Research } \\
\text { and Experimental } \\
\text { Development (R\&D) } \\
\text { Defined as all creative } \\
\text { and systematic activity } \\
\text { undertaken to increase } \\
\text { scientific and technical } \\
\text { knowledge as well as to } \\
\text { develop new applications. }\end{array}$ & $\begin{array}{c}\text { A1. } \\
\text { Fundamental Science } \\
\text { Research undertaken } \\
\text { primarily for the } \\
\text { advancement of scientific } \\
\text { knowledge, without a } \\
\text { specific practical } \\
\text { application in view. }\end{array}$ & $\begin{array}{c}\text { A2. } \\
\text { Applied Research } \\
\text { The same, but with a } \\
\text { specific practical } \\
\text { aim in view. }\end{array}$ & $\begin{array}{c}\mathrm{A} 3 . \\
\text { Experimental Development } \\
\text { The use of the results } \\
\text { of fundamental and } \\
\text { applied research directed } \\
\text { to the introduction of } \\
\text { useful materials, devices, } \\
\text { products, systems, } \\
\text { and processes, or the } \\
\text { improvement of } \\
\text { existing ones. }\end{array}$ \\
\hline
\end{tabular}

Source: Table structured upon the basis of information retrieved from OECD and UNESCO reference-listed sources.

applied research and experimental development, whilst UNESCO coins as generic term for statistical purposes Scientific and Technological Activities (STA) defined broadly as... all systematic activities which are closely concerned with the advancement dissemination, and application of scientific and technical knowledge in all fields of science and technology, that is the natural sciences, engineering and technology, and to the medical and agricultural sciences (NS), as well as the social sciences and humanities (SSH)... Activities included under STA terminology are classified in five main groups: A. Scientific Research and Experimental Development (R\&D), B. Education and Formation, C. Information and Science and Technology Documentation, D. General Interest Data Retrieval, E. Other S\&T Services. Group A. activities are organized as Fundamental Science, Applied Science and Experimental Development, being the main criteria to differentiate Fundamental and Applied Science from Experimental Development (ED) the ED purpose focused on the introduction of new applications (new materials, new technologies, etc.) (UNESCO, 1977).

As marked in bold letters in Table 2, three constant ideas appear in this group of definitions, being the first the notion referring to the purpose... develop new applications... namely innovations, that appears either in the generic R\&D definitions as in the Experimental Development description, supporting the view of $\mathrm{R} \& \mathrm{D}$ as embryonic technology phase. The second constant appears in the Applied Research field determined as... research undertaken with specific practical aim in view... while the third constant is visible as in both sources' definitions 
sets the use of research results is allocated in the Experimental Development arena, either by producing new products, etc, their introduction (diffusion) or the improvement of existing ones. Taking these three fundamental ideas to the Technology dictionary entries comparison, coincidence is found being two specific mentions to physical devices in the online sources.

The Technology term analysis favors the idea to advance forward, from the scattered activities analysis scenario, into a formal MOT Theory comprising MOT' construct configuration as a principal component shaped with characteristics of a multi-construct theoretical net that interweaves diverse streams of thought as exemplifies the Factors of Production view of Technology as a Capital representation with an expected return on investment, the Resource View that introduces the notions of Technology as tangible/intangible assets moving the concept into the ownership dimension and investment representation in the Balance Sheet, and the Technology Life Cycle principles in which stages of development are identified for Technology, introducing the embryonic $R \& D$ phase from which new/improved results open the space for the innovation management venue including entrepreneurship as a key activity-and a field with its own operational principles such as seed capital and platforms such as Business Incubators and Technology Parks-centered at the core of the risk-taking environment of innovation' transition into the market arena.

\subsection{Management Process. The MOT Construct' Actionable Component}

\subsubsection{Introducing the Management View}

Management of Technology construct is by nature established at the core of the context of Management Theory. Looking into both its principles and its operational components, help out to identify the meeting point of MOT's two main components. In the construct' technological milieu analysis, lingers on the theoretical air the disturbing view of Technology as a passive representative of a factor of production-Capital - that to be productive requires a Labor actionable platform. Such idea is illustrated at its time, by Charles Babbage' reference to "...the extent of a factory ought to consist of such a number of machines as shall occupy the whole time of one workman in keeping them in order and in making any casual repairs..." (Babbage, 1832). The word technology does not appear in the quote, however, the idea expressed reveals a fragment of a technological environment in transition that lead into changes on the matter of Technology' conception, by extending the focus further on from using Technology to managing Technology as a firm' resource. Such a state of affairs fostered other moments of discovery in which, from ordinary events of production activities happening along an everyday working context, come to light new theories facing the profit creation challenge through the quest of efficiency improvement to attain high productivity rate growth.

The rising of managerial decisions to improve efficiency undertook by early car industry is a set piece of illustration of a technology-based management 
practice introduction. Thus, the known as classical Era of Management Theory is say to emerge in 1908. The early stage of this Theory is referred to as Fordism (Taylor, 1919) by means of the Assembly Line' as efficient operational practice introduced into the car industry mass production - that turns to provide the basis for the emergence of Taylorism also known as Scientific Management-lead into a theory focused on workflow' analysis and synthesis applied to improve efficiency in labor productivity at task unit level (Taylor, 1919), soon after refined by Gilbreth through their time and motion study contributions in quest of efficiency as cost reduction driver (Gilbreth, 1921). Meanwhile, in the context of metalworks are introduced Fayol's Principles of Management oriented to increase the efficiency and effectiveness of the management function itself, establishing the basis of an articulated... doctrineadministrative... (Fayol, 1917). As observed, the common scenario of these management view ideas' emergence is identified in the field of manufacturing, authored by professionals in Mechanical Engineering, being then established an early connection between technology and management.

\subsubsection{The Managerial Process: MOT' Actionable Component}

La capacité essentielle des grands chefs est la capacité administrative (Fayol, 1917).

Established on this thought, the theoretical sphere of efficiency is translated from the workflow to an emergent managerial activity positioning the administrative function at the firm' highest level of authority. Fayol considers the importance to establish as soon aspossiblean administrative doctrine... il importe donc de etablir le plus tôt possible une doctrine administrative... reflected on his... Principles et éléments d administratio ... where, inspired on 14 operational principles bearing resemblance to military ones, determines five essential management functions that became the backbone on which Management Theory, its variations, derivations, extensions, ramifications, sequels or/and adaptations evolved from then on. Referred to as... Eléments d administration: 1) Prévoyance 2) Organization 3) Commandement 4) Coordination 5) Contrôle... following a numbered sequence, Fayol's five essential functions configure a managerial process that starts with the prevision or anticipation of activities to be performed registered in a programme $d$ action that includes all the firm' operations, services and functions oriented to provide easiness to the use of the firm's resources as well as to select the best means to employ to attain the goals. In a hundred years span of time, the idea moved from its inter-firm border view, to the inter-business partners synchronized management practices, as staged since early XXI Century by management process operating through the firm's functions, operations and activities, extending its internal area boundaries to external business partners through activation of common business practices of the kind of the ones included in the Supply Chain Management strategy, that further on contributes to configure business networks. Being Technology recognized as a firm's resource, the connection with the Management process is established either at strategic 
firm unit dimension-articulated to the managerial process of the firm' full resources suite-as at tactical and operational resource unit level to be managed following the structural organization' pattern adopted, as exemplified by observable plans-programs-projects for areas as Human Resources Management, Finance Management and Logistics Management among others.

\subsubsection{The Management Process' Constructs}

Fayol's managerial process grants structure to the managerial activities. Based on this powerful contribution, definitions of each stage, descriptions, re-naming, adaptations, derivations, notes, comments to the notes, etc, flourished widely in the management related literature, while Fayol' original stages and its sequence remains as an inspiration after a hundred years of being released. Thus, for this reason, the very source of the management function' constructs, enters as a basic referent into the convergence space of both constructs where links as stablished to configure MOT' structural functions, being complemented by the equivalent definitions displayed in one of the English language most used text books on the subject, coincidentally authored by engineers, where a re-interpretation of Fayol' original functional-oriented notion of Administrer, c'est prévoir, organiser, commander et controller is presented through the expression of the idea focusing mainly on a single resource performance and a single function operation as follows... Management is an art of getting things done through and with the people in formally organized groups. It is an art of creating an environment in which people can perform and individuals and can co-operate towards attainment of group goals. Management is the process of reaching organizational goals by working with and through people and other organizational resources. (Koontz, O’Donnell, \& Weihrich, 1988).

The constructs presented in Table 3 reflects the connection between a category of theoretical view on Technology and a correspondent management function operating as the actionable component-verb-of the management functions as are considered processes (planning, organizing, controlling) and activities (directing, coordinating) carried out to achieve a particular end of and in the organization' interest.

\subsubsection{Management and Technology Constructs' Linkage = MOT}

MOT construct is begot by the linkage between two different and independent constructs whose singular characteristics-acting unconnected-attain an additional interdependent character as work together in a single unit. The linkage view differs from the merger or fusion perspective that refers to the combination of two components by addition or absorption joined into one, being mantech an example in point, eliminating so individual boundaries. Management and Technology linkage is registered in a research work carried out by Joan Woodward between 1953 and 1957, that as declared in the 1958 resulting publication... was the first attempt in Britain to discover whether the principles of organization laid down by an expanding body of management theory correlate 
Table 3. The management process constructs.

\begin{tabular}{|c|c|c|}
\hline Essential functions & Fayol, H. (1917) & Koontz, H., O’Donnell, C., H. \& Weihrich, H. (1988) \\
\hline $\begin{array}{c}\text { PLANNING } \\
\text { Prévoyance/Prevision }\end{array}$ & $\begin{array}{l}\text { Process conducted to anticipate activities to be performed, to be } \\
\text { registered in a plan or course of action, that includes all the firm' } \\
\text { operations, services and functions oriented to provide easiness to } \\
\text { the use of its sources as well as to select the best means to employ } \\
\text { to attain the defined goals and objectives. }\end{array}$ & $\begin{array}{l}\text { "Planning is deciding in advance-what to do, when to } \\
\text { do \& how to do. It bridges the gap from where we are } \\
\& \text { where we want to be". It is an exercise in problem } \\
\text { solving \& decision making. Planning is determination } \\
\text { of courses of action to achieve desired goals. }\end{array}$ \\
\hline ORGANIZING & $\begin{array}{l}\text { Process that gather all useful components required for a firm' } \\
\text { operations: materials, tools, capital and personnel. Considers two } \\
\text { main dimensions: Materials Organization and Social Organization, } \\
\text { being in consequence focused on the coordination of activities } \\
\text { with resources as key action to move the plans formulated into the } \\
\text { implementation phase. For doing so, establishes a structure of } \\
\text { working relationships that allow organizational members to work } \\
\text { together to achieve organizational goals, determining as well how } \\
\text { an organization' resources can be best used, particularly human } \\
\text { resources. }\end{array}$ & $\begin{array}{l}\text { It is the process of bringing together physical, financial } \\
\text { and human resources and developing productive } \\
\text {, relationship amongst them for achievement of } \\
\text { organizational goals. To organize a business involves } \\
\text { determining \& providing human and non-human } \\
\text { resources to the organizational structure. }\end{array}$ \\
\hline $\begin{array}{l}\text { DIRECTION } \\
\text { Commandement }\end{array}$ & $\begin{array}{l}\text { Direction function-at top of the hierarchy-is profiled through } \\
\text { the authority and the unity of command principles, the director' } \\
\text { distinctive features are the statutory authority enacted by the } \\
\text { function, and the personal authority derived from intelligence, } \\
\text { knowledge, experience, moral value, commandment skills, services } \\
\text { granted, etc. A single direction is a necessary condition for action } \\
\text { unity, forces coordination and efforts convergence. }\end{array}$ & $\begin{array}{l}\text { Directing is a management function through which the } \\
\text { management instructs, guides and inspires the } \\
\text { employees by communicating with them, oversees the } \\
\text { performance for goals achievement and leads the } \\
\text { s employees to perform efficiently and contribute to } \\
\text { their optimum for the achievement of organizational } \\
\text { objectives. }\end{array}$ \\
\hline $\begin{array}{l}\text { COORDINATION } \\
\text { Supervision }\end{array}$ & $\begin{array}{l}\text { Coordinate is to unify and harmonize all the firm' activities in } \\
\text { order to facilitate its technical, commercial and financial } \\
\text { operations through all the firm' functions. It is to provide the } \\
\text { necessary financial resources, facilities, equipment and materials } \\
\text { required for procurement, production and sales. } \\
\text { Supervision-implies overseeing the work of subordinates by their } \\
\text { superiors. It is the act of watching \& directing work \& workers. }\end{array}$ & $\begin{array}{l}\text { Supervision involves directing and overseeing the job } \\
\text { of subordinates which normally include, rank and file } \\
\text { employees, blue collar technicians and workers } \\
\text { carrying out their operations in an organization. This } \\
\text { function is implemented with the purpose to ensure } \\
\text { that subordinates operates efficiently and effectively in } \\
\text { correspondence to the organizational goals established } \\
\text { to their key function. }\end{array}$ \\
\hline CONTROL & $\begin{array}{l}\text { Consists on confirm the enactment of the firm' operations } \\
\text { activated by the program defined, the complete social body } \\
\text { operation, the orders provided and the management principles } \\
\text { application, with the purpose to identify the deviations and errors } \\
\text { to take corrections for further elimination. Control activities are } \\
\text { run by the direction and its hierarchized levels applying registers } \\
\text { of statistical use, documental and personal communication means. } \\
\text { Applies to all activities and all levels. }\end{array}$ & $\begin{array}{l}\text { "Controlling is the measurement \& correction of } \\
\text { performance activities of subordinates in order to make } \\
\text { sure that the enterprise objectives and plans desired to } \\
\text { obtain them as being accomplished". }\end{array}$ \\
\hline
\end{tabular}

Source: Table structured upon the basis of information retrieved from H. Fayol (1917) and H. Koontz et al. (1988), listed sources.

with business success when put into practice (Woodward, 1958). This is to be said a seminal piece on the topic that take aim at the core of MOT functions as revealed by its stated structure purpose to... Look at the division of responsibilities between line supervision (widened to include the whole of management) and the technical specialists who apply technology to the production process and at the factors which determine the relationships between them, The idea of a linkage between technology and other knowledge' fields reached fertile soil 
upon the appearance of the United Nations' Manual on Development Projects that introduces the powerful idea of considering development projects... within the context of the entire economic system of which they will form a part... (United Nations, 1958), providing a methodology structured into three articulated units: Market Feasibility Study, Technical Feasibility Study and Financial Feasibility Study. This guidance allows standardized results-investment projects proposals on the paper-to input the financial evaluation phase for development-investment-founding proposals assessment, fostering further on the emergence of systematic project-management techniques, oriented to align the investment entrusted to results assurance.

At the time of this study, Management of Technology' search engine marks close to $4,340,000,000$ results ( 0.65 seconds) while a search by reference of the term as Technology Management marks close to 4,510,000,000 results (0.64 seconds) (Google. Management of Technology entry), (Google. Technology Management entry). A browse on those terms lead to a territory whose geography is shaped by materials such as education programs, course materials, explanatory graphics and diagrams, articles, cases, experiences, consultancy ads, research projects, definitions, reports, books, proceedings' content and a variety of other resources whose full revision defy boldness. However, awareness rises in regard to the importance of an interdisciplinary field surfacing with an amassed information capital available through more than 9 million results on line. Given this circumstances, a number of definitions on the topic appears as diverse disciplines develops influence on the assigned purpose of the activity as illustrated by an online source' simultaneous consign of three versions of the term referred to as technology-management (igi.global.com), and by a 2001 publication of the United Nations Industrial Development Organization (UNIDO, 2001) designating with the name Management of Technology a 2001 a report structured by a selected group of papers dealing with technology transfer, technology acquisition and the impact of technology for economic growth (MOT' procedures/consequences), with no visible definition contained.

Nevertheless, even when most frequent component is consequential-used for a given purpose-most of the definitions identified as designated by the name of Technology Management in a general review of books and articles on the topic, reflect as common characteristic the reference to the coverage of some or all the managerial functions in relation with the technology term, as exemplified by a particular definition founded online that shows a trace of MOT spirit by integrating at least two theoretical components of the management functions and one of technology' theoretical referents-TLC-even when not completed by its purpose statement... Technology management covers all aspects of organizing technology knowledge, technology forecasting, technology development, technology commercialization and technology usage through the technology life-cycle... (igi.global.com).

Set at industry-specific technology view (IT/Systems) the definition issue 
evolves to a next level when the notion of construct appears in the MOT field, as is identified in two research papers set at industry and organizational function respectively, both referring to systems as the related technology. The first paper, published in a Health Care Systems book reports hard efforts to locate... discussions or definitions of technology management... consigning that in doing so... a rigorous content analysis was conducted searching in a data base of 255 articles and reading 47 related dissertations... upon this bases the mentioned research presents a definition of the technology management construct that covers various theoretical interrelation among its components as well as its purpose statement... technology management may be defined as a holistic and integrated application of engineering, science and management capabilities to strategic life cycle management of new and relevant product and processes technologies in order to shape, as well as to accomplish, the goals and objectives necessary for business success (Eisler, 2005). The second paper set at a specific management function, centers attention on the HR-Technology Systems construct (Florkowski, 2018), being for that reason considered outside the scope of the present research.

Moving from the definitions' descriptive-explanatory grounds into the sphere of abstract mental representation of ideas understood as... the configuration in theoretical, abstract terms, in conditions of other theoretically related constructs... as previously introduced in this research, the Management of Technology construct is expected to be configured by both, the linkage notion (of) as well as by the two theoretically related constructs (management + technology), working as a unit. Disclosing consistency with the theoretical basis of the Technology and the Management constructs conducted so far, it is introduced into this analysis the National Research Council (NRC), USA definition... MOT links engineering, science, and management disciplines to address the planning, development, and implementation of technological capabilities to shape and accomplish the strategic and operational objectives of an organization... (National Research Council (1987), as a suitable construct to provide structure to the broadest display of the relations established among the independent constructs' components that results in MOT' elements. This reasoning rises the analysis level to explore-with broad brush strokes-the linkages between T\&M constructs as required action to reach reasonable-supported results to be used as a fundamental input of MOT construct' Nomological Net assemblage.

\section{Methodological Frame}

The research interest' complexity takes to the surface the necessity to use an appropriate analytical process with a matching set of actionable resources customized to develop a supported-reasonable answer to the RQ. In short, a methodological challenge is envisioned. So far the content of the text developed reveals that the ideas have been articulated following a logic reasoning structure built upon a system of research methods-bring into play to deal with the requirements imposed by the nature of the research interest focused on meaning-identified 
with the deductive logic-structural arrangements applied to the articulation of the sequence: introduction by means of a referential frame remarking the meaning-importance/constructs' of interest milieu individual analysis/construct' connection in MOT' construct/methodology and so forth. Following this sequence, it would be expected that a full immersion into the methodological platform follows before the development of the results and discussion segment, however, awareness rise from the chance to open a path soon to be most distracting to the research focus becoming as a result in a sort of paper-within-a-paper. The concern was settled by tradeoff. The body of the paper presents the research's process and the works' action map, whilst a broad explanation of the Methodological frame developed to fix the intervening constructs positions is featured in a dedicated space labeled Annex 1.

Based on Cronbach' ideaintroduced previously in this paper regarding the importance to elaborate the nomological netin which a construct occurs for better understanding of a theoretical construct (Cronbach \& Meehl, 1955), this methodological frame encompasses two main operational works being 1) the process carried out, by which Management of Technology' Nomological Net is configured until its assemblage is satisfactory concluded and 2) the identification of the resulting Management of Technology Nomological Net' structural features in terms of theoretical components, their linkages' pattern and their grouping shape. Following the decision criteria established for the Methodological Frame description, is introduced the Research' General Methodological Process. Figure 3 displays the bare workflow of the research' process carried out to configure MOT' construct Nomological Net, differentiating two blocks of action being the analytical one focused on the information collection and information processing works needed to input the second block of synthesis, where the Nomological Net assemblage takes place providing visibility to its configuration as a required echelon to reach the stage of MOT NN' structural features identification, from where the theory grounded answer for the RQ emerges.

In Figure 3 a three stages' analysis process contains the operational activities related with the information management requirements, being the Conceptual Frame sketch is positioned as the process' first stage whose five requirements determine the nature of the literature on the matter to be integrated as information sources, a distinctive element-as recalled would be-that in this type of analysis documented information sources plays as numerical data sources does in studies of quantitative nature. The stages' linkage is established through a loop like continuous iterative process of sources revision-followed to benefit information extension/refinement/verification-that grants a dynamic nature to the workflow along the three process' stages. Nurturing the Methodological Frame segment of the paper structure, the observable results of the first stage' workflow are the Research Question (RQ) statement, the Research's Paradigm setting and the selection of the suitable Research Approach upon which the analysis is performed. 


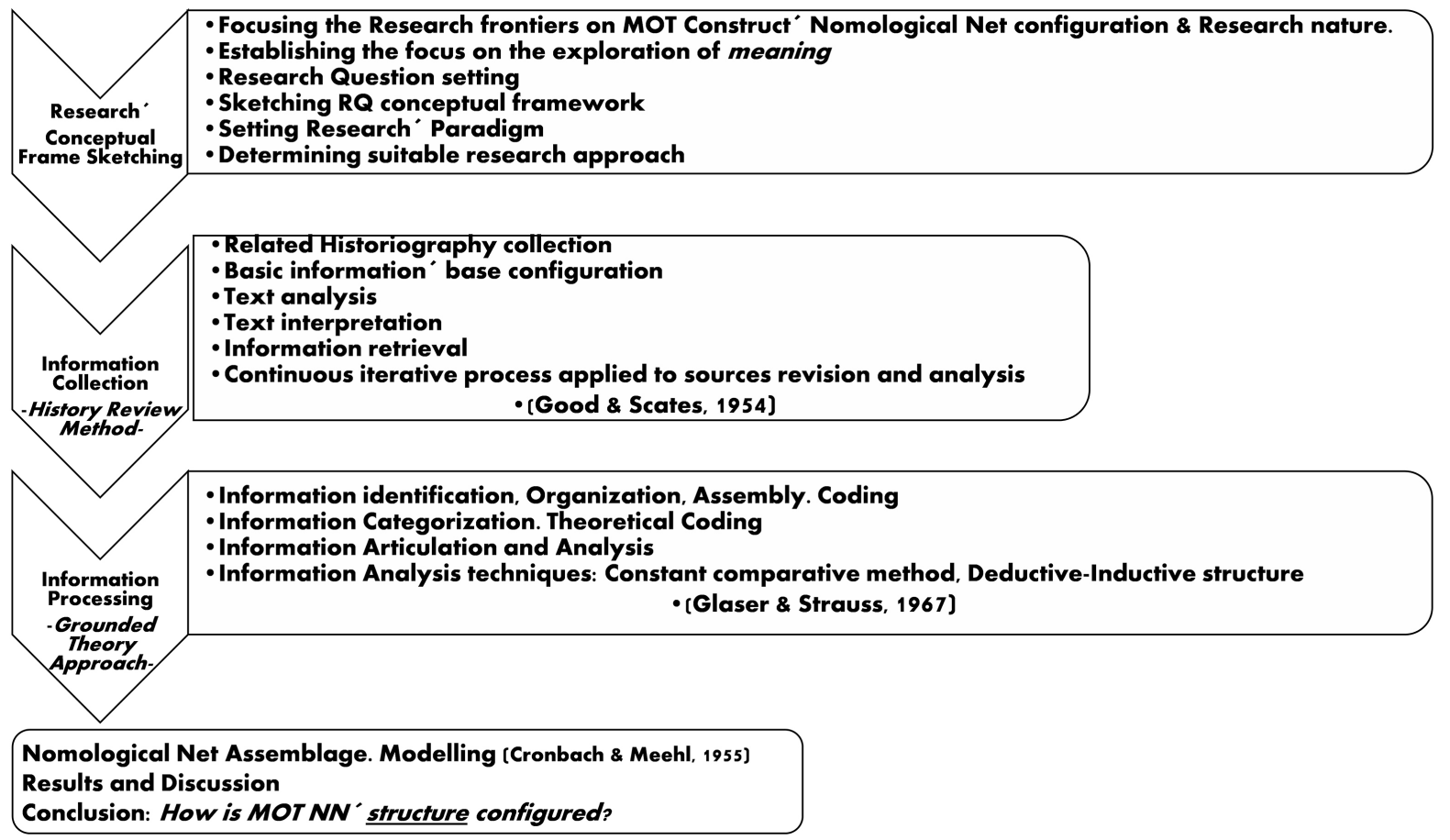

Figure 3. Research' general methodological process. In a nutshell.

Results are set in the domain of the Economic Paradigm displayed in the Construct's Milieu segment articulated in correspondence to the research question' nature upon the frame of Qualitative Research (Weber, 1921/1978), and in the selection of its Grounded Theory Approach (Glaser \& Strauss, 1967), (Strauss \& Corbin, 1990), as suitable methodological frame to apply for the information' processing phase.

Being set the course for the works, the second stage of the process refers to the hands-on activity related with information collection based on the History Review Method (Good \& Scates, 1954). Information Collection stage is considered satisfactory finished when saturation is identified. The organization and categorization of the information operation is undertaken applying the referred Grounded Theory' coding technique as the tactical procedure for resulting categories' articulation whilst disclose the interactions among them. The resulting categories are withdrawn through an intense information/data processing tabulation and networking tests, being considered completed as redundancy appears. Both outcomes of this coding process are necessary input to move forward into the phase of the modelling of MOT' construct Nomological Net.

The dynamic nature of the operations conducted within the research process is mapped in Figure 4, clearly marking the two main mental processes' building blocks defined by the research' conceptual framework: the analysis and the synthesis blocks, being the first conducted following the History Review Method procedures for information collection as well as the Grounded Theory Approach for information coding processing into categories as the manageable unit for MOT construct assemblage considered to be the synthesis-process block. In the 
resulting map is recognized the convergence of the individual systems of methods into an articulated system of methods customized in correspondence to the Research Question' requirements, due to this reason the Complex Systems view that distinguishes the research interest, leaves its mark on the dynamics of the actions carried out to manage the consistent system of research methods.

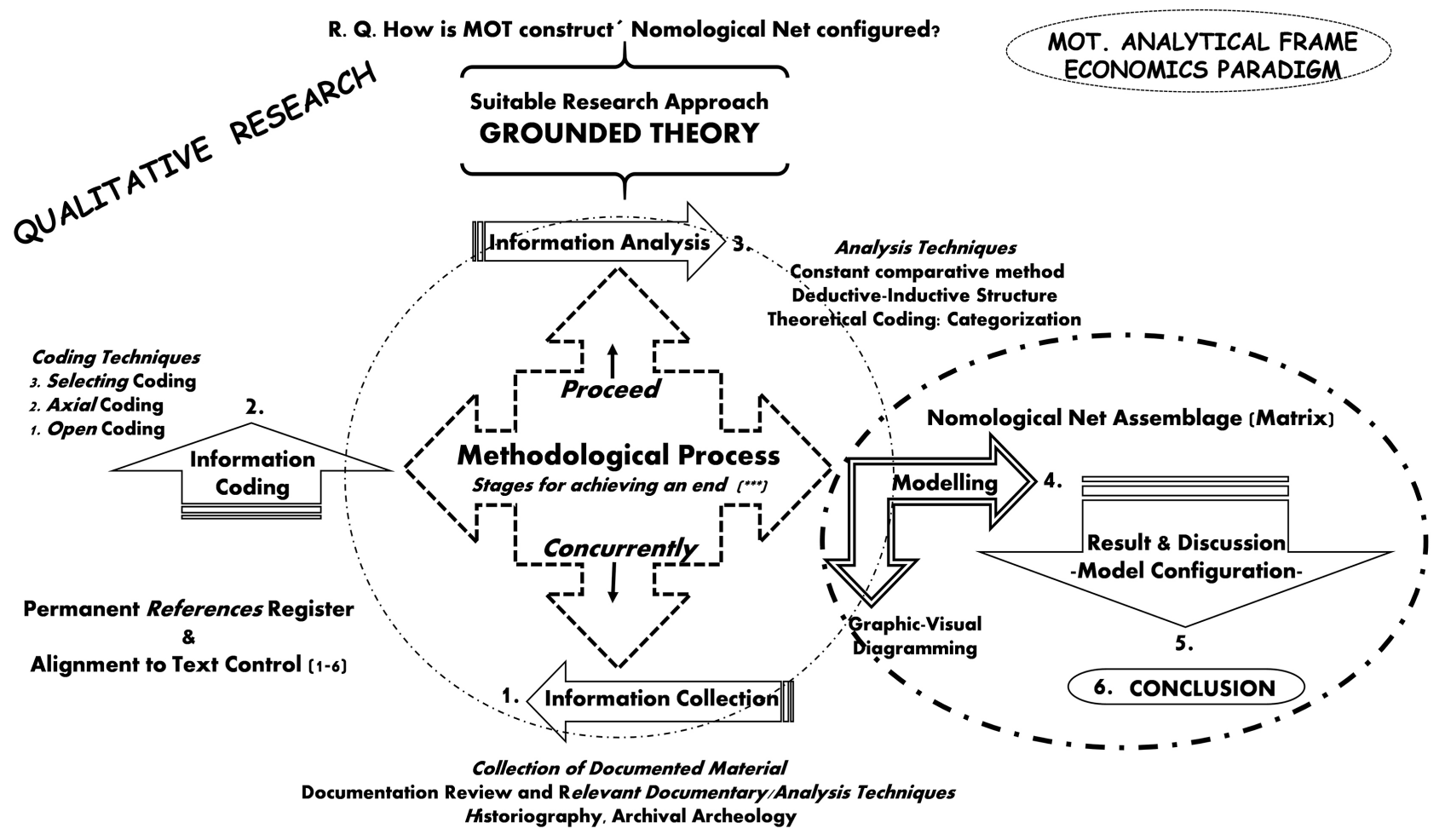

Figure 4. Research' operational methodology' Map. complex systems view.

\section{Analysis and Results}

\subsection{Shaping the Technology Construct}

The historical perspective review method (Good \& Scates, 1954) applied to trace the technology role-needle-on-the-haystack-for the period allotted, seems to be useful as it pictures a specific economic milieu in which technology is seen under the political economy dominance lens, albeit come into sight a significant interest by theorists of the time in regard to Technology effect as they seem to be clear of both its influence on the economy as well as its impact in the production trench so as to ensure benefit for the countries, and competitiveness for the industry. Being at this point aware of the need to escape from a historical preoccupation regarding technology importance, as the exploration made carries conviction, it is history precisely the source of reasonable basis to identify the presence of two complementary discourses, in reference to specific role and effects outlooks of Technology, identified either at macroeconomic and at microeconomic level as result of its sphere of influence-country/industry/firm level-working in constant interaction as the first crafts the economic, legal, fiscal 
and so on contextual policies to be actionable by the second's operations. Thus, this segment analysis opens the door to the idea of a bi-dimensional working arena in which the MOT construct is set, being the admission of such a dual operational dimension is a significant component of the key rationale that fits the requirements to work on MOT construct' nomological net.

Taking these thoughts into Figure 5, is consider as the proper means to gain visibility regarding the interconnections of three main autonomous interactive blocks namely the Macroeconomic Dimension, Microeconomic Dimension and Technology comprising its life cycle stages, each of them maintaining its' dynamic pace, such representation mirrors a Complex Systems Structure, as recognized by the range of interacting disciplines and fields playing in a nonlinear system where... changes in effects are disproportional to the changes in the causal element(s)... (Byrne \& Callahan, 2013).

Recent works related to MOT' field of knowledge introduce the Complex Systems perspective to frame technology-related analysis as it is... considered to be the suitable approach to organize the theoretical body of knowledge involved in the selected topic of analysis, as a previous step to identify properties that emerge from the systems interaction, which cannot be drawn from the properties of the parts as a unit... (Erosa, 2018a). Diagram 5 discloses the type of order profiled as result of the systems' interactions while put on view the non-linear connections among the theoretical components creating a comprehensive Map of the Theoretical scaffold in which this paper is framed on, with two circles differentiating clearly the dual operational environment in which the construct of interest is set.

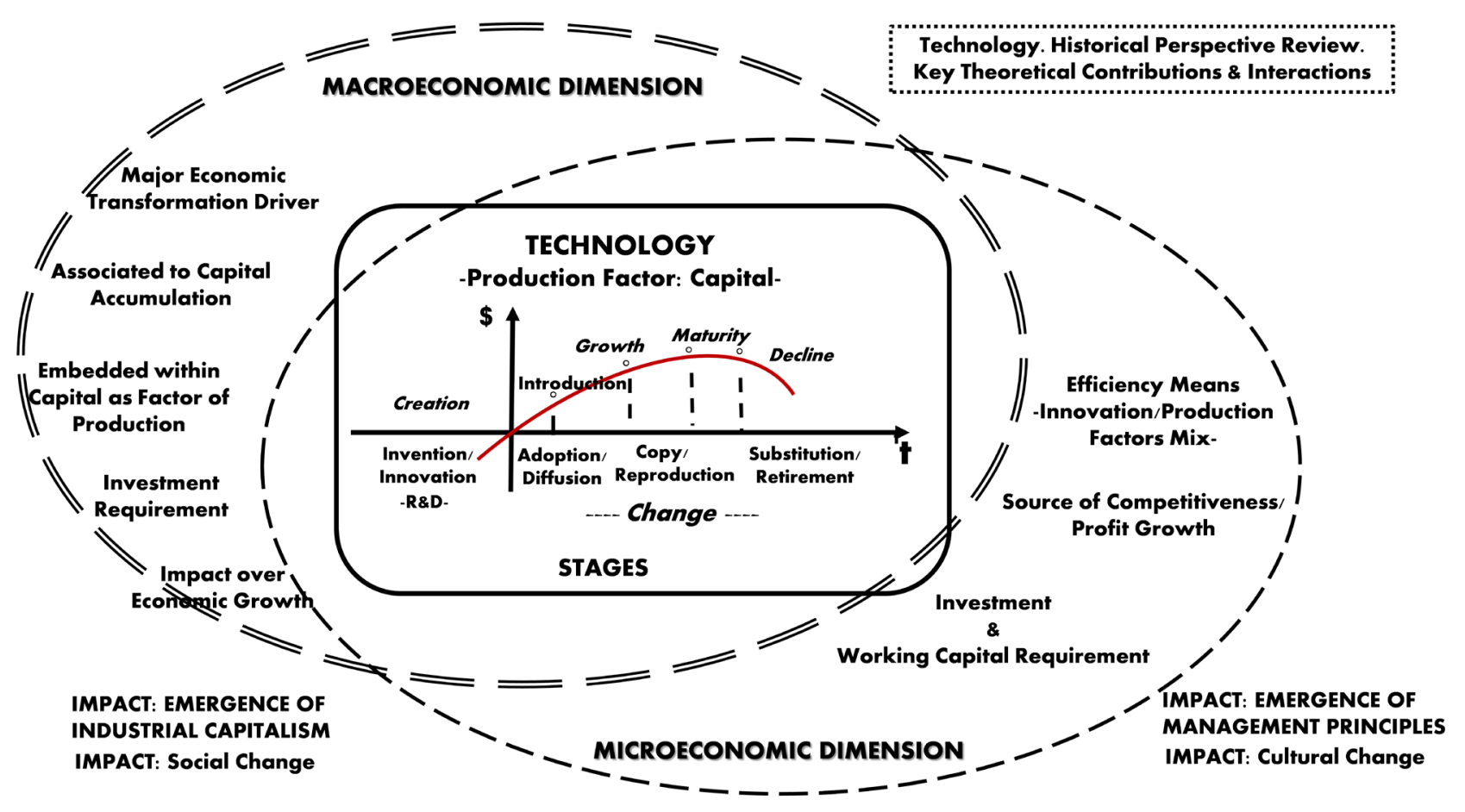

Figure 5. MOT key constructs' interaction. research study' theoretical scaffold map. 
Figure 5 configuration also portrays the interplay between deduction and induction views along the analytical process that lead to identify the dynamic interaction among the three major conceptual blocks: Macroeconomics, Microeconomics and Technology life cycle stages positioned at the core of the continuum. A first reading from a general to a particular view of the figure-a deductive reasoning perspective also referred as top-down logic-show that within this Complex System, each of the components follows their own dynamic pace, constantly moving back and forwards from nation/economic development component-to-competition market driver-to-a four stage life cycle resource that is constantly evolving. In the figure, the Macroeconomic Dimension emerges as the first major component of the order of theoretical ideas due to its nature as the area that measures the economic activities of a Nation at aggregate level, creating for such a purpose indicators that gauge the Economy Value (GDP), identifies the structure or composition by sector, monitors its trading position (Trade Balance) and displays its wealth or Capital Formation, among other economic performance signs useful for Economic Policies operability.

Technology from the Macroeconomics view acts as a core element of Regional Economic Development Policies formulation, Fiscal benefit policies, National R\&D Guidelines, Capital Investment Policies, and so on. The importance of Technology as development axis varies among countries turning visible in actions of the type of being introduced in Government Structures at highest levels under figures such as Ministry of Technology or Government Agencies of the kind operating Technology Plans at Country/Region/City/Public Service area of influence. Structures of such nature differ in purpose to those focused on Science $\mathrm{R} \& \mathrm{D}$, even when is expected to complement or nurture one to the other.

Observable examples on the matter are found in documents issued in a variety of countries by a number of Government agencies and public institutions, usually named Technology Plan. Being clearly understood that public policies issued at Macroeconomic level have an impact on Microeconomic level, it is crucial to have in mind that these array of policies are set at the firm' external environment, thus, being out of the reach of their control, introducing instead courses of action that require attention to be internally managed at the highest individual firm level. Research results focused on economy and technology, uphold the idea that a macro level technology view orientation seems to be a source of understanding in pertain to the effects or impact of the technological changes on the economy, regardless the reasons-determinants-and social processes that lead to such changes that could even take into a new economic paradigm emergence as the digital phenomena illustrates, while at micro level the production function view targets the wealth creation purpose as it is oriented to enhance the positive effects of technology over industry/firms' efficiency/productivity parameters (Erosa, 2018a).

The interactive deductive dynamics standpoint guides the figure reading, from nation/economic development component, into the competitive market driver 
perspective moving the analysis focus into the Diagram second major component, the Microeconomics dimension identified as the playground for competition actions that influences Markets/Industries/Firms' creation-changes-eliminationreconfiguration, etc., either by profiles' modifications or by changes in the amount of the supply or the demand sides propelled by innovation' impact. In other words, reach the arena in which Technology drives and reacts to changes in supply and demand influencing innovation efforts in a two-way path widely known as the technology-push (R\&D based innovation creates a market) and market-pull (R\&D innovation driven by market needs) strategies (Betz, 2003; Brem \& Voigt, 2009). During the upper period of the XX Century the role of innovation in competitiveness has been introduced and soundly analyzed into/by the business-focused literature as various works exemplify (Shoen, 1967; Foster, 1986; Burgelman, Maidique, \& Wheelwright, 2000). The core component of such a deep influence and dynamic economic-market disruptor is a Capital Factor in the form of tangible or intangible resources observable as products-operation resources-production processes, broadly referred to as Technology, interacting in the competitive arena through its own dynamic defined by its life cycle stages. Technology' operational context perspective as competition driver is understood when economists' view regarding the business purpose is introduced... firms are in search of profits... (Robinson, 1953).

A second reading of the figure is focused on bridging the Macroeconomic theoretical dimension to the Microeconomic Dimension in which the firm' competitive environment is set, sharing the two spaces Technology is placed as third key analytical component being considered as a resource with its own life-cycle dynamics expressed by the innovation cycle stages.

The notion of the view of Technology as a firm' resource is rooted in the Theory of the View of the Firm as it considers... the firm as a collection of productive resources... the physical resources of a firm consist on tangible things-plant, equipment, land and natural resources, raw materials, semi-finished goods, waste products and by-products, and even unsold stocks of finished goods... the disposal of which between different uses and over time is determined by administrative decision... it is largely in this distinction that we find the source of the uniqueness of each individual firm (Penrose, 1959). Is in this dimension where occur interactions among key theoretical components such as the value chain and competitive advantage concepts-from Competitive Theory (Porter, 1998)the firm's attitude to face its business environment through specific strategies enabled, supported and/or based on Technology as conceived in Strategic Management Theory (David, 2017), the subtle differentiation of Technology' observable manifestations from Resource View Theory (Wernerfelt, 1984; Barney, 1991), as well as the introduction of principles such as those of Diffusion Theory (Leonard-Barton \& Rogers, 1981; Leonard-Barton, 1982), focused on the process by which an innovation is adopted by a certain group. Following this order of ideas, the individual sphere is reached through the Technology Adoption Model 
(TAM) concepts that deals with the matter focusing on the fundamental concepts of Technology Use, Technology Usage and Technology Utilization (Davis, 1989).

On grounds of the theoretical referent articulated applying the Complex Systems view sketched on Figure 5, at this point is reasonable to consider that the term Technology refers to the representation of a production factor designated Capital, observable in form of tangible and/or intangible assets put on view as products, production means, operational processes, intellectual property rights and related know-how, to be used by organizations/firms with wealth/benefit creation purposes. Following this notion, Technology assets are considered as a resource whose interaction with the resource' platform of the firm is expected to be utilized to improve productivity and gain competitiveness or create new business models, thus, increasing benefits/profits and strengthening competitive position.

The review carried out to articulate a Construct' Milieu as a process to take into surface MOT' construct, suggests a long-term influence of the flux of economic thought of the eighteen Century on the Technology theoretical milieu across time. From the ideas put forward from the techno-historiography revision, as brief as it might considered to be, two main resulting features emerge as suitable to be introduced into the MOT' nomological net exploration, the first relates to the performance set that shapes a dual technology dimensions' of influence-macro and micro level-while the integration of the innovation related thought, clearly determines technology' source of origin and its path from being an idea-invention-to the profit generation stage and its role as development driver means.

This line of reasoning is consistent with UNESCO' statement highlighting the... A successful modern economy is founded on a strong scientific base that has the ability to convert scientific research and knowledge into products and services brings social and economic benefits... (UNESCO, 2012). Then, there is an emergent complementary perspective within the research interest, as the nomological network comprises two setting dimensions and four life cycle phases of one of the two main components of the MOT construct, being the later the factor of production/resource/subject receptor of management actions, namely Technology.

At this point of analysis is possible to identify that the construct is comprised by a number of components from two different nature being the first identified as determinants 1) Technology as a resource/factor of production and by 2) Management as the frame of the actionable operations through which benefit/profit generation is expected to be set in motion, while the next component' types are consistent with the consequential view 3 ) working interconnected on a dual-overlapped economic dimension carrying out the role of 4) economic development driver/wealth creation means.

\subsection{The Management of Technology Construct}

Technology' construct analysis put on view the context that fostered Manage- 
ment offspring, in which the Management of Technology notion as a single unit, was envisioned in the engineering field as come off in Woodward' work (1958), and articulated as a body of knowledge as result of the attention given to the matter by a task force standing for four engineering and technical commissionsregistered for publication in the National Research Council (1987) report on Management of Technology. At this point, the research study progresses a step forward as the analysis process evolves into a synthesis process by combining the ideas from technology' construct $(\mathrm{T})$ features to its linkage with management (M) as the construct of actionable nature to be combined with, to configure a distinct object of thought (MOT). Getting these conceptual strings into a shared frame is admitted to be crucial to weave a new contextualization of a single conceptual unit. Thus, this segment comprises a broad description of the interconnections between technology and management functions that configure MOT components in terms of an ensemble of operating management functions applied to resources identified under the generic term of technology-as these perform within the referred economy and organization' frames. The resulting Management of Technology structural functions are displayed in Table 4.

Table 4. MOT’ structural functions. technology \& management links.

\section{Level: Strategic}

MANAGEMENT\} Prevision/Prévoyance/Planning Function. (Fayol, 1917)

TECHNOLOGY\} Economic View (Schumpeter, 1942; Kaldor, 1966)

Is the managerial function focused on the process conducted at top strategic level to define strategic objectives on the matter and anticipate technology related activities to be performed by the firm/organization registered in a plan or course of action, that includes all the firm' operations, services and functions, oriented to provide easiness to the use of its technology platform as well as to select the best technology-based means to be employed to attain the defined goals and objectives. Technology plan is a main referential input for Investment programs' projects-valuation-founding activities, for operational technology-related budget planning/control, and for assessment modes and measurement criteria definitions Applies either al macroeconomic as microeconomic level.

Level: Strategic/Tactical

MANAGEMENT $\quad$ Organization Function. (Fayol, 1917)

TECHNOLOGY\} Firm's Resource View (Penrose, 1959; Wernerfelt, 1984; Barney, 1991)

Is the managerial function focused on the activities oriented to articulate and alignall useful technology-based-related components required by a firm' operations: materials, tools, capital and staff. Considers two main dimensions: Materials Organization and Social Organization, being in consequence focused on the coordination of technology-based-related activities with resources identified with a technology platform, as key action to move the business and technology plans into the implementation phase. 
Level: Strategic/Tactical

MANAGEMENT $\}$ Direction Function. (Fayol, 1917)

TECHNOLOGY\} Firm's Resource View (Penrose, 1959; Wernerfelt, 1984; Barney, 1991)

MANAGEMENT OF TECHNOLOGY

Technology Direction Function

Is the managerial function that enacts the statutory authority concerning management of Technology based-related activities set in motion to accomplish organization' strategic objectives and determined goals, as well as the personal authority to define actions to assure that the personnel assigned to technology-related activities and operations works in accordance to the processes, operations and quality standards determined by the organization and/or its operational business sphere. The Technology Direction function is accountable for the formulation, implementation and control of Technology plans, policies and derived technology transfer/technology change/technology portfolio management programs and the resulting projects of technology nature. Direction function is connected vertically to the organization' top management level as staff or as an organizational unit while is horizontally connected with all the other functional areas and/or with business partners' peers.

\section{Level: Operational}

\section{MANAGEMENT $\}$ Coordination Function. (Fayol, 1917)}

TECHNOLOGY\} Firm's Resource View \& Technology Adoption Model (Penrose, 1959; Wernerfelt, 1984; Barney, 1991; Davis, 1989)

\section{MANAGEMENT OF TECHNOLOGY}

Technology Coordination Function

Is the managerial function focused on technology related activities' harmonization within the technology unit and among the technology unit and organization functional structure' units. A distinctive feature of the function is supplies' procurement as instrumental means to provide-as in plan/program/deal/deliver to user-the necessary technology-related resources, its suitable facilities and its correspondent technology platform as a necessary component for organizational objectives and goals accomplishment. The function encompasses supervision as the combined activity focused on overseeing the work of subordinates by their superiors to prevent errors and/or to solve emergent problems on day-to-day operations.

Level: Operational Use: Strategic Input

MANAGEMENT\} Control Function. (Fayol, 1917)

TECHNOLOGY\} Firm's Resource View \& Technology Adoption Model (Penrose, 1959; Wernerfelt, 1984; Barney, 1991; Davis, 1989)

\section{MANAGEMENT OF TECHNOLOGY}

Technology Control Function

Is the managerial function that follows up the firm operations' enactment activated by the program defined, the complete social body operation, the orders provided and the management principles application, with the purpose to identify the deviations and errors to take corrections for further elimination. Control activities implies assessment and measurement actions run by the direction and its hierarchized levels utilizing registers of statistical use, documental and personal communication means. Applies to all activities and all levels.

Source: Table structured upon the basis of the reference listed sources. 
Technology \& Planning Link. Acknowledged as the planning function emergence, Fayol' Prévoyance evolves to the firm's Policy definition, Strategic Planning practice to formulate Strategic Plans and further on to the Strategic Management Models that integrate the Plan Formulation with its Implementation and Control (David, 2017). A cascade of available techniques, methods and guidelines have been incorporated into the firm' planning arena mainly along the last half Century when the function permeated the firm' functional structure producing specific customized plans/programs for the short and the long term. Is in this given conditions that emerges as an observable result of the management action over a strategic resource the Technology Plan, from which Project Management rises as the methodological frame-in a range that goes from Feasibility Studies to Engineering Project-that articulates and control project' implementation along with the investment applied to Technology in its broadest view or to a particular Technology life-cycle stage as Innovation-product and/ or process-due to its role as a source of competitive leadership.

Connected to the strategic level' core as business plan' crucial support and/or enabler component, Technology Planning begins with the Technology Strategy definition, concept that evolves giving place to the emergence of fundamental notions of the kind of the alignment principle, synchronization and technology readiness. Technology strategy is determined-defined, using as decision input the external business' context analysis and the correspondent organizational/functional/operational technology audit conducted to have a full map of the technology assets, the state of the technology platform life-cycle, supported by technology forecasting, trend analysis and technology mapping techniques or other methodological aids of the kind. In the investment front, technology portfolio is configured and established as the investment management tool that provide key information regarding the ROI of each technology platform' element included in the portfolio, in addition to the state of technology in terms of obsolescence, depreciation and tax policies among other issues. Useful tools introduced into the Technology Planning process are illustrated by Technology Forecast techniques and by a number of Project Management programs developed in-house and a wide array of others available on the market, being some key observable outcomes the Technology Plan, the Technology Audit register, the Technology Portfolio and the Engineering/Technology Projects operating as actionable units of decisions' implementation.

Technology \& Organization Links. Moving forward, the Managerial Process enters into an action territory that deals with the functional-operation of the firm labelled Organization focused on the coordination of activities with resources as key activity to move the plans formulated into the implementation phase. Focused on determining how technology-based-related resources can be best used, within the given position determined in the organizational structure, technology organization function establishes a suitable structure of working relations that benefit internal and external interaction among organization' members, to work in synchrony with partners and stakeholders to achieve strategic 
objectives and goals. The activities coordination venue of the Organization stage refers to the formalization of a structure of positions aligned to the functional requirements to attain the goals established for each strategic objective' accomplishment. This structure is reflected in an Organizational Chart that defines the functional roles of individuals as well as the authority, decision and accountability at function-activity-task-operation levels through a derived series of instruments named Manuals (Organizational Manual, Operational Manual, and the sort...) commonly complemented by standardized processes, and by internal operational norms and regulations. This component is the basic input to coordinate diverse types of resources - materials, technology, capital, staff, intangible/know-how-being of its core interest those represented by the staff through an organizational function referred to as Human Resources Management, that involves activities as job position description-profiling-valuation, recruitment, selection, integration, assessment, promotion, etc., as well as the follow-up of the operational expenses that represents within the operational and administrative costs to be considered for budget management and control. This function is closely related to payroll management and control, as well as to the efficiency measurement or productivity assessment.

MOT linkages to Organization function takes place at resources organization environment, focusing on the technology platform' definition-set up-operational implementation-processes' definition-management-results assessment and related activities, whilst in the activities component works for MOT' functional allocation within general and/or specific social body configuration-Organizational Structure or architecture-in accordance to the firm characteristics either as Staff function or integrated as strategic transversal Divisional unit, tactic function or operational activity through the given hierarchy or to be outsourced if required. This is the sphere of convergence of technology culture influences, technology change management, technology adoption, training programs and where works on the technology-knowledge related field development are attended as illustrated by of MOT' professional competences definition, job positions profiling, business process reengineering programs-manuals-processesprocedures-operations' definition and diffusion. This is also the playground where one of technology' major breakthroughs emerged in the management field by means of the Enterprise Resource Planning (ERP) system that move to automated territory the Human Resources Management processes and operations working together and in sync, with other organizational units.

Technology \& Direction Links. Being Technology closely related to investment and financial decisions Technology Direction function is-formal or as staff-positioned at top management level, permeating down hierarchy to the executive and operational levels for direct enactment and operation. The function interacts with internal organizational units either in the role of formal structure component as in the role of head of specific projects development and/or team-work and steering committees' conduction being commonly assigned as well as the firm' representant in external private and public working 
groups of the kind. As business strategy enabler and supporter, Technology Direction' decisions comprise either actions to align business strategy with its performance environment as well as derived actions focused on technology decisions alignment to the business strategy. Operates in the territory of Technology Plan formulation, implementation and control. A key activity of the function is to conduct the activities oriented to establish priorities over the strategic technology objectives and goals on which resources will be allocated and staff activities will be channeled, monitored and assessed. Technology Direction works on the standards of performance and measurement criteria definitions that input the strategic analysis of Technology' operational outcome. At the core of this structural function are the Technology Change Management Program and the Technology Adoption policies, regulations and structured activities.

Technology \& Coordination Links. This is considered to be said the moment of true technology-related function for being the one that is directly positioned at individual level where the concepts of Use, Usefulness and Ease of Use of Davis' (1989) Technology Adoption Model (TAM) pushes forward theory and planning into person' every-day technology operation reality even when working as team member. The scenario of technology adoption and change management programs implementation, technology culture emergence and technology-based productivity improvement actions and steering committees' appearance and disappearance. Technology Coordination function covers, enables and/or support the firms physical resources coordination in order to smooth the procurement flow required to input both back stage and front desk processes. Here is the land of automated warehouse management and control, technology-traced inventory of all kind management, products' automated picking, sorting processes, suppliers' management performed over an information technology/systems platform that might be integrated into an ERP system. Concentrates the to-be-assessed performance operations, activities, projects, programs and the sort defined by the upper echelons, while keeping them tuned as the effort for objectives and goals achievement is in progress. Technology Coordination function gains complexity as is extended to Supply Chain Management operational environment that requires all integrated business partners to align and synchronize common processes for materials and information flows management.

Technology \& Control Links. Technology Control function distinguish itself of other technology structural managerial functions by being simultaneously a resource (all and each component integrated to the firm' technology platform) over which control and assessment actions are exercised, and a means (Information Systems infrastructure and/or ERP option or a given specialized application acting as follow-up and assessment mechanism also called model) through which the firm operates its assessment and control platform based on measures and indicators that produce information regarding its consistency with the defined business objectives, its correspondence to established business processes and practices, its harmonization with the array of internal and external standards determined and its results' closeness to the determined goals satisfaction. 
This is the space to find Technology Audit activities set in motion to either identify the characteristics and conditions of the technology platform, input Technology Portfolio upgrade, the feasible adaptive response of Technology based available resources to the external environment demands/changes and to strategic objectives' achievement, being the resulting information of most importance as inputs decision making in regard to Technology Transfer (buying, selling, leasing, outsourcing, etc.) Technology Strategy (leader, follower, adapter, imitator, etc.), Technology Investment management, and about the role to be play by Technology resources as new business creator (as in electronic commerce ventures). Technology Control Function is extended into the diagnosis of firm' current technology skills and know-how to identify possible gaps to narrow or eliminate through education and training interventions as well to create communication conditions to profile a new technology culture or to reshape the existing one.

\subsection{The MOT Construct' Nomological Net Configuration}

Keeping the focus on the Nomological Net configuration, this segment features the interlocking set of constructs which constitute a theory referred to as a $\mathrm{No}$ mological Net. This influential idea was featured by Cronbach \& Meehl (1955) for construct validity purposes in the context of psychological test validation however, for this research' interest, turn out to be a tactical-operation resource introduced as a suitable option to carry out works on the construct configuration direction involved in a theoretical context characterized by constructs' void or imprecision. Operational activities on shaping/mapping theoretical constructs interconnections are a necessary step to take in the process followed to build up a fairly supported input to gain understanding in regard to the construct' meaning.

The Nomological Net (NN) modeling process, implemented on grounds of the Theoretical Frame as well as with the methodological platform crafted in alignment to the RQ nature, achieve results that reveal the $\mathrm{NN}$ structure in theoretical units, its linkages-within, between and among-and its derived observables. In Figure 6, solid lines consign the relation of each one of the clustered component-constructs to their own component-constructs set, to illustrate its specific dynamic working as an independent theoretical block marked by an individual bordered-box. NN configuration as represented in the graphic model, contains a first building block embodying the Management construct formed by its five essential functions and a second building block comprising the Technology construct shaped by the five main theoretical categories identified through the Grounded Theory' coding procedure-principles applied for processing the information collected on grounds of the RQ requirements, as described in Annex 1. The linkage of these two-main-constructs theoretical building blocks, marked by two dotted arrows, activates the appearance of a third individual theoretical unit termed Management of Technology construct. 


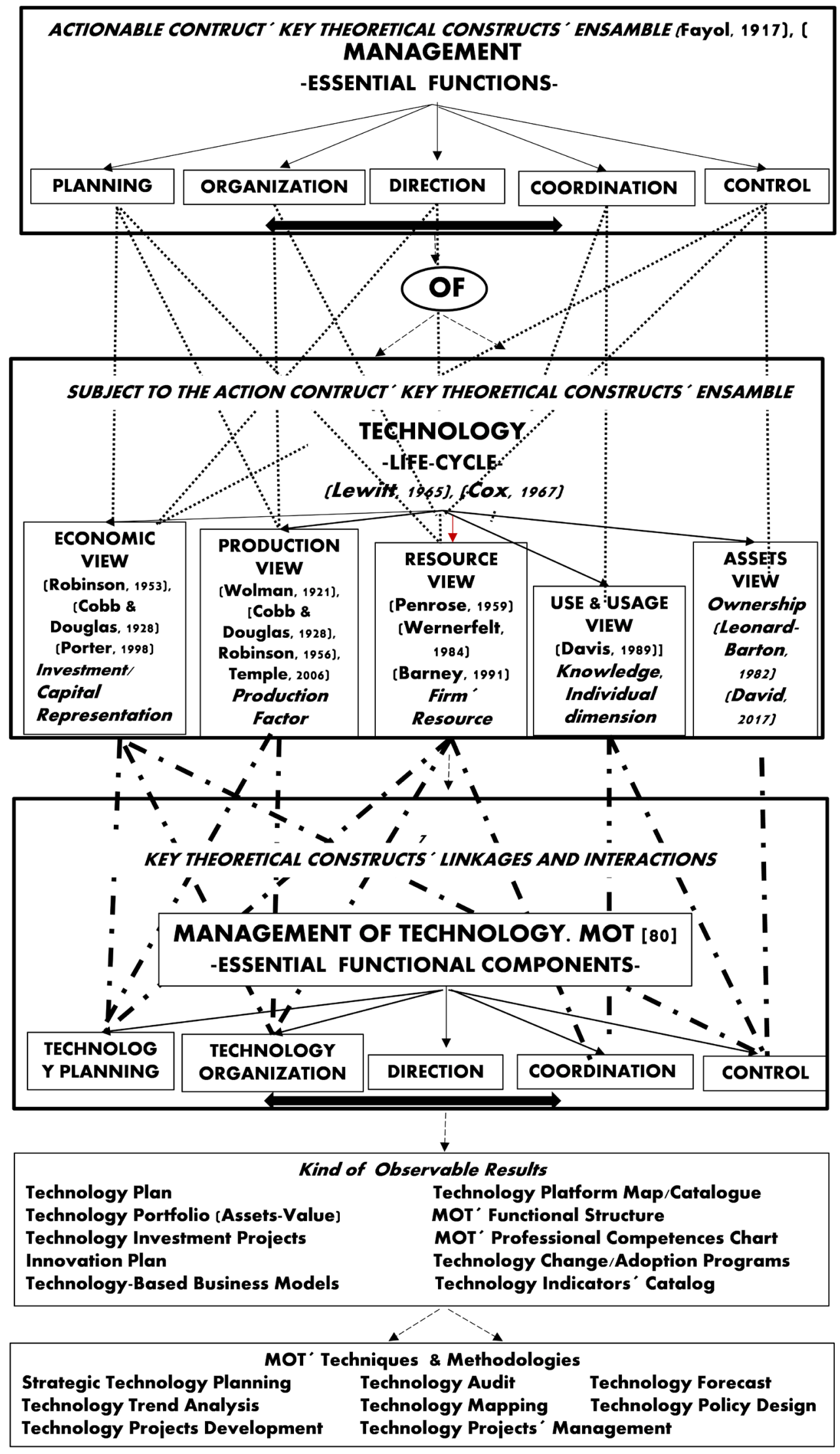

Figure 6. Management Of Technology (MOT) Construct' Nomological Net Configuration (Erosa). 
The links established among constructs disclose consistency with the Nomological Network law referent to... relating different theoretical constructs to one another (Cronbach \& Meehl, 1955), by including both interaction layers: 1) main construct to main construct layer-as in between-and 2) construct' individual components to each other, as in among them. The first layer is the level at which takes place the linkage between constructs from where MOT as a single conceptual item is modelled, whilst the second layer contains the number of linkages among one to each other' components that permeates into the emergent construct as the observable set of Management of Technology' structural functions. Being settled the linkages between MOT' main constructs (solid lines) denoted by the of proposition, their correspondent components (solid lines), and the connections among them (dotted lines), NN's rule to relate each of... the main constructs' observable properties to each other, is consider to be covered by the resulting links established among the two $(\mathrm{M}) \&(\mathrm{~T})$ building blocks and the emergent observable construct: MOT (intermittent lines) identified as output of causal-relationship nature.

At this point complexity increases for being MOT construct' special feature its dual-different constructs composite nature, moved into the workable arena as required by the NN Law referred to... theoretical configuration constructs to observables, as in this is the site where theory meets practical grounds. The theoretical implications of Management of Technology activities are observable through the array of results able to be seen as a Technology Plan, a Technology Project, a Technology Investment Portfolio, a Technology Audit report and others as the ones included in the first box at the bottom of Diagram 6, that are feasible to move into the activities and/or individual' measurement and indicators assessment dimension. These observables-referred as deliverables in MOT' operational field-are developed by means of application of a given set of MOT techniques, methodologies and/or technical procedures, as the ones displayed in the box at the very bottom of the NN figure.

Figure 6 put on view a complex Management of Technology' Nomological Net resulting from the convergence of a two-constructs-two-disciplines' in a relation established by linkage, formed each of them by five correspondent components, whose individual linkages shape MOT' structural functions through which the theoretical concepts moves into the operational field in which the techniques, methodologies and technical procedures are applied. Special mention is required for the multidisciplinary origin of the Technology construct configuration build up by the articulation of a theoretical set that goes along its allocation in the economic paradigm (economic development, capital and production theories), as its managerial-business focused view (resource view, competitive, product life cycle theories) and the science view (technology origin). This multi-knowledge field' roots, grants an adaptative nature to Technology construct identified by its application in a given number of knowledge fields. Even when a simple three-box linkage shapes the construct' $\mathrm{NN}$, it is the linkage 
among the set of components the origin of its complexity from which construct' unique modular-workable feature emerges providing a flexible environment to engage in MOT activities either by as function-module mode (Technology Planning, etc.) or/and integrated into the formal organizational line (MOT Division, SBU, Department, Unit, etc.), the staff advisory level (Technology Planning Advisory), the one-time project team (Technology Change Program) or in the consultancy area related to any of the Technology Functions (Project Formulation/Management).

\subsection{MOT's Construct in Action}

Pushing the boundaries set by the Research Question nature, NN quality assessment venue is broadly introduced through its application into an operational MOT scenario following the Trochim and Land (1982) research design' quality criteria suggested by Stegmann (2014) for NN evaluation purposes in terms of five conditions: 1) theory grounded, due that for each of its linkages a directional effect is justifiable by a theory, as is visible in Diagram 6;2) situational, for being the two main constructs and their linkage' outcome involved in the particular context in which they perform; 3) feasible, since this $\mathrm{NN}$ is mainly structured by theoretical components that represent actionable processes, it is feasible to manage specific groups of theoretical components as illustrated by the modular attribute identified; 4) redundant, as any specific process can be activated several times-due to the flexibility attribute-either running at their own pace at any time required by the MOT activity and at in any mode of alignment, synchronization, intermittence, continuous flow and in any type of role as enabler, support, complement, key-central axis, and so forth, 5) efficient, NN worth is identified by its role as MOT scattered component' articulation figure centering the construct into a unique meaning environment, as well as for its flexibility to be used as a roadmap in which MOT structural functions and correspondent techniques, methodologies and procedures are allocated. An illustration of how these criteria works for MOT' construct is briefly outlined in Annex 2.

The workable venue of MOT' Nomological Net was applied following a single fiber selecting for such purpose the Logistics Function as its technology platform integrates physical material movement base technology and an information flows transmission enabler technology (technology resources), being the complexity of the application raised by introducing SCM as the operational environment to integrate the set of electronic operations \& processes, ID standards and electronic messages in due course. In this setting a strong technology knowledge base is recognized as a crucial component of the logistics technology platform. The function's complexity lead to fundamental operational decisions in regard to outsourcing either the complete function (a third partner logistics mode), a partial detachment mode (services supplier for an specific logistics operation), a combined management/operational mode (controlling logistics management decisions operating through a services supplier platform), by the 
full control of the function assuming the investment requirements and operational risks (Logistics function ownership mode) to make reference to the most common operational decisions. A broader description of this application is presented in Annex 2.

\section{Conclusion}

Management of Technology has been taken here into the theoretical dimension by means of its reference as a Concept, or set of ideas that represent general categories or types of things in relation to technology and management convergence. At the core of this notion are the complex and rich ideas and theories referred to as premises on which the MOT concept is based, rising the awareness that this is the territory on which the research interest is set, for being still open the discussion around the meaning and meaningfulness of the concept, and the introduction to the ideas and theories in which is based, out of sight. This paper's novelty come into surface by its focus on the meaning of a term that reflects a specific managerial practice working at strategic, tactic and operational levels, whose theoretical foundations grants a dimension of a body of knowledge articulated in accordance to the managerial essential functions applied. Taking Management of Technology into theoretical grounds results as well a novelty by moving the research center of attention into the domain of the abstract ideas in which the subject matter is implanted. Being engaged in a construct exploration is an immersion exercise into the cohesive set of theoretical dimensions that configure an abstract idea or subject matter. Addressing the Management of Technology construct required an in-depth revision of the reasons that gave rise to the development of managerial practices and techniques focused on the efficient use of a competitive resource identified as technology. Such reasons are found in the field of economic thought, explained in terms of benefits/profit creation and investment return either at firm level as at economy aggregate level.

The innovative theoretical approach of this study introduces unique methodological challenges either on the research process to follow as on the multi-method's harmonization operation, in consequence the methodology crafted to deal with the specific interest is considered a second novelty presented here. The research process conducted to address the conceptual premise at issue that is consigned in this paper, provides an in-depth view of how the construct is interweaved in a complex theoretical net that supports its meaning, while describes its linkages with the theoretical components on which is based and from which derives Management of Technology's structural functions. The methodological frame's closure, displaying Management of Technology construct's Nomological Net configuration process is considered to furnish the... How is MOT's Nomological Net configured? with a supported, sufficient and satisfactory answer, as fits the question's workable process view, following in a step-to-step detailed methodology developed in correspondence to the operationalization of the question of research's interest stated as... How is MOT's Nomological Net Structure 
configured? posed in the construct's internal composition dimension.

A supported, sufficient and satisfactory answer is provided for the RQ by the resulting Management of Technology Nomological Net put on view in a Figure in terms of the numerous theoretical constituents in which the construct is implanted and of the linkages established between and among them in consequence of the nature of the structural functions to be performed. The assemblage of this sets of elements brings to the net a modular structural shape displaying constructs, interactions and derived observable pieces. MOT's Nomological Net configuration displayed in the diagrammed figure reveals the presence of a multi-facet construct with links that sharp the boundaries in which each individual facet performs, as illustrated by the Technology Planning construct's dependence-links with the economic and production theoretical roots of the technology construct, while Technology Organization construct's dependence-links are established in the space of the Production and Resource View of the same technology construct, and so on. This unique compositional structure influences the emergence of the construct's distinctive traits regarding modularity and flexibility whose effect permeates into the operational field as structural functions able to perform either as a combined matching set as individually.

The configuration of the resulting net is anchored in theory of diverse disciplines of knowledge conferring to the construct a theoretical density visible through the wide field of the practical activity that influences, as identified also by the presence of Management of Technology activities at the macroeconomic dimension in terms of technology policy and strategies definition, or contributing to structural changes on the economy-illustrated by the emergence of the digital paradigm - as well as in the technology innovation planning, measurement and transference to the economic flow by means of the entrepreneurial fiber. This trait of the net configuration ignites a dynamic of triple helix-circular interaction as its theoretical economic-based nature foster the appearance of changes in markets and business contexts strongly related to technological changes opening operational spaces for MOT structural functions, the ones that in turn are expected to have an effect at economy's aggregate level and in firms at individual level (Erosa, 2018b). MOT's nomological net theoretical density bring out the construct's adaptability to work in a differentiated number of fields either in technical, manufacturing and engineering as in business and services environments, being for this reason considered to be a contribution to gain understanding upon the magnitude and importance of this novel managerial field.

Exploring the meaningfulness of the Management of Technology construct in theoretical terms favors the notion of the presence of a differentiated body of knowledge articulated in a nomological net, whose modularity, flexibility, adaptability and theoretical density ease the way to the operational environment, well-appointed with its own set of principles, processes, techniques and interaction rules either at macro as at microeconomic level. From these conclusions a contribution is expected to be set on the Management of Technology' theory 
building domain, as is consider to benefit understanding on the configuration of the theoretical net that gives to the Management of Technology construct its structural dimensions, identified as the managerial essential functions that made the abstract idea visible through its observable results' application.

\section{Implications for Further Research \& Limitations}

The configuration of the Management of Technology construct' nomological net, is considered to be a useful contribution for bridging the theoretical gap that might become tangible for research' operational definition works. Opening MOT' conceptual perspective, turns to be a novel approach that provides, for further research interests', a key input in the theory building direction regardless the challenges for thematic expansion imposed by the many theoretical threads involved. Since the early stages of the paper development, awareness has been risen regarding the presence of a clear understanding about the idea that the construct boundaries setting and its nomological net configuration, are fundamental requisites to move forward into the construct validity stage, which at this point remains a formidable challenge for the Management of Technology research agenda.

\section{Conflicts of Interest}

The author declares no conflicts of interest regarding the publication of this paper.

\section{References}

Babbage, C. (1832). On the Economy of Machinery and Manufactures (p. 175). London: Charles Knight. https://doi.org/10.5479/sil.975430.39088015716483

Barney, J. (1991). Firm Resources and Sustained Competitive Advantage. Journal of Management, 17, 99-120. https://doi.org/10.1177/014920639101700108

Bass, F. (1969). A New Product Growth for Model Consumer Durables. Management Science, 15, 215-227. https://doi.org/10.1287/mnsc.15.5.215

Beal, G. (1957). The Diffusion Process. IOWA State. Special Report No. 18, Agricultural Extension Service, IOWA College.

Betz, F. (2003). Management Technological Innovation: Competitive Advantage for Change (2nd ed., p. ix). Hoboken, NJ: John Wiley \& Sons, Inc.

Brem, A., \& Voigt, K. (2009). Integration of Market Pull and Technology Push in the Corporate Front End and Innovation Management-Insights from the German Software Industry. Technovation, 29, 351-367.

https://doi.org/10.1016/j.technovation.2008.06.003

Brentano, F. (1995). Psychology from an Empirical Standpoint (2nd ed.). Abingdon-onThames: Routledge.

Burgelman, R., Maidique, M., \& Wheelwright, S. (2000). Strategic Management of Technology and Innovation (3rd ed.). New York: McGraw-Hill Companies.

Byrne, D., \& Callahan, G. (2013). Complexity Theory and the Social Sciences. The State of The Art. London, New York: Routledge. https://doi.org/10.4324/9780203519585

Chandler, A. (1962). Strategy and Structure: Chapters in the History of the Industrial En- 
terprise. Cambridge, MA: MIT Press.

Cobb, C., \& Douglas, P. (1928). A Theory of Production. The American Economic Review, 18, 139-165.

Cox Jr., W. (1967). Product Life Cycles as Marketing Models. The Journal of Business, 40, 375-384. https://doi.org/10.1086/295003

Creswell, J. (2013). Qualitative Inquiry and Research Design: Choosing among Five Approaches (3rd ed.). Thousand Oaks, CA: Sage.

Cronbach, L., \& Meehl, P. (1955). Construct Validity in Psychological Tests. Psychological Bulletin, 52, 281-302. https://doi.org/10.1037/h0040957

David, F. (2017). Strategic Management. Concepts and Cases (11th ed.). Upper Saddle River, NJ: Prentice Hall.

Davis, F. D. (1989). Perceived Usefulness, Perceived Ease of Use, and the User Acceptance of Information Technology. MIS Quarterly, 13, 319-340.

https://doi.org/10.2307/249008

Decker, S. (2013). The Silence of the Archives: Business History, Post-Colonialism and Archival Ethnography. Management \& Organizational History, 8, 155-173. https://doi.org/10.1080/17449359.2012.761491

Denzin, N. K., \& Lincoln, Y. (2003). Handbook of Qualitative Research. Thousand Oaks, CA: Sage.

Djellal, F., \& Gallouj, F. (2014). The Laws of Imitation and Invention: Gabriel Tarde and the Evolutionary Economics of Innovation. halshs-00960607f.

Eisler, T. J. (2005). E-Health Care Technology Management: A Multifactorial Model for Harnessing E-Technologies. In J. Tan (Ed.), E-Health Care Information Systems: An Introduction for Students and Professionals (pp. 406-438). San Francisco: CA: Jossey-Bass.

Encyclopedia of Marxism at Marxism.org. https://fr.wikisource.org/wiki/Livre:Fayol, Henri - Administration industrielle et g \%C3\%A9n\%C3\%A9rale, 1917.djvu

Erosa, V. E. (2012). Dealing with Cultural Issues in the Triple Helix Model Implementation: A Comparison among Government, University and Business Culture. Procedia-Social and Behavioral Sciences, 52, 25-34.

https://www.sciencedirect.com/science/article/pii/S1877042812038931

https://doi.org/10.1016/j.sbspro.2012.09.438

Erosa, V. E. (2018a). Online Money Flows: Exploring the Nature of the Relation of Technology's New Creature to Money Supply-A Suggested Conceptual Framework and Research Propositions. American Journal of Industrial and Business Management, 8, 250-305. https://doi.org/10.4236/ajibm.2018.82017

Erosa, V. E. (2018b). The Impact of Technological Change on Modern Economy. [Влияние технологических изменений на современную экономику]. Russian Foreign Economic Journal, No. 10-2018, 7-23.

Fayol, H. (1917). Administration industrielle et générale. H. Dunod et E. Pinat, 1917: 2-170. https://fr.wikisource.org/wiki/Administration

Felton, A., \& Stickley, T. (2018). Rethinking Risk: A Narrative Approach. Journal of Mental Health Training, Education and Practice, 13, 54-62. https://doi.org/10.1108/JMHTEP-06-2017-0043

Florkowski, G. (2018). HR Technology Systems: An Evidence-Based Approach to Construct Measurement. In M. R. Buckley, A. R. Wheeler, \& J. R. B. Halbesleben (Eds.), Research in Personnel and Human Resources Management (Vol. 36, pp. 197-239). 
Bingley: Emerald Publishing Ltd. https://doi.org/10.1108/S0742-730120180000036006

Foster, R. N. (1986). Innovation: The Attacker's Advantage. New York: Summit Books. https://doi.org/10.1007/978-3-322-83742-4

Foucault, M. (1969). The Archeology of Knowledge [L'archéologie du savoir]. Editions Gallimard: 12-115-117.

Galambos, L. (1970). The Emerging Organizational Synthesis in Modern History. Business History Review, 44, 279-290. https://doi.org/10.2307/3112614

Gilbreth, F. (1921). Motion Study: A Method for Increasing Efficiency of the Workman. New York: D. Van Nostrand Company.

Glaser, B., \& Strauss, A. (1967). The Discovery of Grounded Theory: Strategies for Qualitative Research. New York: Aldine Publishing Company.

Godin, B. (2014). Invention, Diffusion and Linear Models of Innovation: The Contribution of Anthropology to a Conceptual Framework. Journal of Innovation Economics \& Management, No. 15, 11-37. https://doi.org/10.3917/jie.015.0011

Good, C., \& Scates, D. (1954). Methods of Research: Educational, Psychological and Sociological. East Norwalk, CT: Appleton-Century-Crofts.

https://doi.org/10.1037/13206-000

Hardegree, G. (2009). Symbolic Logic: A First Course (2nd ed.). https://courses.umass.edu/phil110-gmh/MAIN/IHome-5.htm

Husserl, E. (2001). Logical Investigations (Vol. I). Psychology Press.

Jones, G., \& Khanna, T. (2006). Bring History (Back) into International Business. Journal of International Business Studies, 37, 453-468. https://doi.org/10.1057/palgrave.jibs.8400198

Judd, C., Smith, E., \& Kiddler, L. (1991). Research Methods in Social Relations (6th ed., p. 46). The Dryden Press.

Kaldor, N. (1966). Causes of the Slow Rate of Economic Growth of the United Kingdom. London: Cambridge University Press.

Kaplan, D. (1972). What Is Russell's Theory of Descriptions? In D. Pears (Ed.), Bertrand Russell: A Collection of Critical Essays (pp. 227-244). New York: Anchor Books.

Kerr, P. (1993). Adam Smith's Theory of Growth and Technological Change Revisited. Contributions to Political Economy, 12, 1-27. https://doi.org/10.1093/oxfordjournals.cpe.a035615

Koontz, H., O’Donnell, C., \& Weihrich, H. (1988). Management (9th ed.). London, New York: McGraw-Hill Series.

Kuznets, S. (1966). Modern Economic Growth (Chap. 1). New Haven, CT: Yale University Press.

Leonard-Barton, D. (1982). Applying Diffusion Theory to The Management of Change. Working Paper WP-1295-82, Alfred P. Sloan School of Management, Massachusetts Institute of Technology.

Leonard-Barton, D., \& Rogers, E. (1981). Horizontal Diffusion of Innovations: An Alternative Paradigm to the Classical Diffusion Model. Working Paper 1214-81, Alfred P. Sloan School of Management, Massachusetts Institute of Technology.

Levitt, T. (1965). Exploit the Product Life Cycle. Harvard Business Review, 36, 37-66.

Mansfield, E. (1968). The Economics of Technological Change. New York: W. W. Norton \& Company.

Marx, K. (1867). Capital. A Critique to Political Economy. Volume I. The Process of Production of Capital. English Edition (1887) (Chap. 14, 237-298). Moscow: Progress 
Publishers.

Mendelsohn, R. (2004). Reflections on Russell's Theory of Descriptions. New Prague Tex. 21/08/2004: 1-26.

Moore, R. (1989). Propositional Attitudes and Russellian Propositions. In J. Bartsch, P. van Benthem, \& B. van Emde (Eds.), Semantics and Contextual Expression (pp. 147174). De Gruyter Mouton.

National Research Council (1987). Management of Technology: The Hidden Competitive Advantage. Washington DC: The National Academies Press.

O’Rourke, M. (2005). Meaning and Meaningfulness. Philosophy 446. Moscow: University of Idaho.

https://webpages.uidaho.edu/ morourke/446-phil/05\%20Spring/Handouts/Philosophi cal/Meaning\%20and\%20Meaningfulness.htm

OECD (1963). Frascati Manual (1st ed.).

OECD (2002). Frascati Manual (6th ed.). Annex III.

OECD (2015). Frascati Manual (7th ed.).

OECD European Commission. Eurostat (1992). The Measurement of Scientific and Technological Activities. Proposed Guidelines for Collecting and Interpreting Technology Innovation Data. OSLO MANUAL (1st ed.).

OECD European Commission. Eurostat (2018). OSLO MANUAL: Guidelines for Collecting, Reporting and Using Data on Innovation (4th ed.). Series: The Measurement of Scientific, Technological and Innovation Activities. Measurement Manuals Series.

Pearce-Moses, R. (2005). A Glossary of Archival and Records Terminology. Chicago, IL: The Society of American Archivists. SAA.

Penrose, E. (1959). The Theory of the Growth of the Firm (4th ed., Chapter II, pp. 21-23). Oxford: Oxford University Press.

Polli, R., \& Cook, V. (1969). Validity of the Product Life Cycle. Journal of Business, 42, 385-400. https://doi.org/10.1086/295215

Porter, M. (1998). Competitive Advantage: Creating and Sustaining Superior Performance (Chap. 1, Chap. 5). Free Press.

Robinson, J. (1953). The Production Function and the Theory of Capital. The Review of Economic Studies, 21, 81-106. https://doi.org/10.2307/2296002

Rogers, E. (1983). Diffusion of Innovations (3rd ed.). Free Press.

Rosenberg, N. (1982). Inside the Black Box: Technology and Economics. Cambridge: Cambridge University Press. https://doi.org/10.1017/CBO9780511611940

Russell, B. (1905). On Denoting. Mind, 14, 479-493. http://www.jstor.org/stable/2248381 https://doi.org/10.1093/mind/XIV.4.479

Schumpeter, J. (1939). Business Cycles. A Theoretical, Historical and Statistical Analysis of the Capitalist Process. New York, Toronto, London: McGraw-Hill Book Company.

Schumpeter, J. (1942). Capitalism, Socialism and Democracy (3rd ed.). London: George Allen and Unwin.

Shank, G. (2002). Qualitative Research. A Personal Skills Approach. Upper Saddle River, NJ: Prentice Hall.

Shoen, D. (1967). Technology and Change: The New Heraclitus. New York: Delacorte Press.

Simons, H. (2009). Case Study Research in Practice. Thousand Oaks, CA: SAGE Publishing. https://doi.org/10.4135/9781446268322 
Stegmann, K. (2014). Constructing Nomological Nets on the Basis of Process Analyses to Strengthen CSCL Research. Frontline Learning Research, 6, 25-33.

Strauss, A., \& Corbin, J. (1990). Basics for Qualitative Research: Grounded Theory Procedures and Techniques. London: Sage.

Tarde, G. (1895). La Logique Sociale. Edition électronique réalisée à partir du livre de Gabriel Tarde, La logique sociale, 1895. Paris: Félix Alcan.

http://clasiques.uqac.ca/classiques/tarde gabriel/la logique sociale/logique sociale part 1.pdf

http://clasiques.uqac.ca/classiques/tarde gabriel/la logique sociale/logique sociale part 2.pdf

Tarde, G. (1903). The Laws of Imitation. New York: Henry Holt and Company. https://monoskop.org/images/3/35/Tarde Gabriel The Laws of Imitation.pdf

Taylor, F. (1919). The Principles of Scientific Management. New York, London: Harper \& Brothers Publishers.

Temple, J. (2006). Aggregate Production Functions and Growth Economics. International Review of Applied Economics, 20, 301-317. https://doi.org/10.1080/02692170600736052

Trochim, W., \& Donnelly, J. (2006). The Research Methods Knowledge Base (2nd ed.). Great Lakes, Midwestern: Atomic Dog Publishing.

UNESCO (1977). A Guide for the Collection of Statistics on Science and Technology. Paris: UNESCO. ST-77/WS/4.

UNESCO (1984). Manual for Statistics on Scientific and Technological Activities ST$84 / \mathrm{WS} /$

UNESCO (2012). Science and Technologies for Knowledge Societies. Consultations of the Director-General with Member States. 26 November 2012: 1.

UNESCO/UIS (2010). Technical Paper No. 5. Measuring R\&D: Challenges Faced by Developing Countries. UNESCO Institute of Statistics.

UNESCO/UIS (2014). Technical Paper No. 11, 2014. Guide to Conducting an R\&D Survey: For Countries Starting to Measure Research and Experimental Development. UNESCO-Institute of Statistics: 9.

United Nations (1958). Manual on Development Projects. New York: United Nations Publication.

United Nations Industrial Development Organization. UNIDO (2001). Management of Technology. Selected Discussion Papers Presented at the Vienna Global Forum, Vienna International Centre, Austria, May 2001.

Vernon, R. (1966). International Investment and International Trade in the Product Cycle. Quarterly Journal of Economics, 80, 190-207. https://doi.org/10.2307/1880689

Weber. M. (1921/1978). Economy and Society. An Outline of Interpretive Sociology. Berkeley, CA: University of California Press.

Webster (1989). Webster's Encyclopedic Unabridged Dictionary of the English Language (Edition 1989: 987 and 1458).

Wernerfelt, B. (1984). A Resource-Based View of the Firm. Strategic Management Journal, 5, 171-180. https://doi.org/10.1002/smj.4250050207

Whitney, W. (1895). The Century Dictionary. An Encyclopedic Lexicon of the English Language (Vol. VIII, p. 390). New York: The Century Co.

https://archive.org/details/centurydictionary08whit/page/n8/mode/1up

Wolman, L. (1921). A Theory of Production. The American Economic Review, 11, 37-56. 
Woodward, J. (1958). Management and Technology: Problems and Progress in Technol$o g y$ (Vol. 3). London: Her Majesty's Stationery Office.

World Bank (2016). World Development Indicators: Structure of Output 2005-2016. Table 4.2. http://wdi.worldbank.org/table/4.2

Yeh, C., \& Inman, A. (2007). Qualitative Data Analysis and Interpretation in Counseling Psychology: Strategies for Best Practices. The Counseling Psychologist, 35, 369-403. https://doi.org/10.1177/0011000006292596

\section{Online References in Order of Citation, Retrieved from}

https://www.britannica.com/topic/social-science

http://philosophy-index.com/philosophy/branches/

https://www.collinsdictionary.com/dictionary/English/concept

https://www.dictionary.cambridge.org/es/diccionario/ingles/premise

http://www.historyofinformation.com/detail.php?id=4491

http://www.historyofinformation.com/detail.php?id=4613

https://thelawdictionary.org/invention

https://www.lexico.com/en/definition/imitation

https://www.etymonline.com/word/technology

https://collinsdictionary.com/dictionary/english/use-technology

https://oxfordlearnersdictionaries.com/definition/english/technology

https://google.com/search Entry: technology definition Google

https://en.wikipedia.org/wiki/Technology

Google. Management of Technology entry

https://www.google.com/search?q=management+of+technology\&oq=managem

$\underline{\text { ent }+ \text { of }+ \text { technology\&aqs }=\text { chrome. } .69 \mathrm{i} 57 \mathrm{j} 017.7439 \mathrm{j} 0 \mathrm{j} 8 \& \text { sourceid }=\text { chrome } \& i e=U T}$

$\underline{\mathrm{F}-8}$

Google. Technology Management entry

https://www.google.com/search?newwindow=1\&safe=active\&sxsrf=ALeKk03gvCGVg Ogy41NJIOrQA2D7qcTEw\%3A1592173918332\&ei=XqXmXtHgE8f0Abx7zAAg\&q=t echnology+management\&oq=+technologu\&gs

https://www.igi-global.com/dictionary/technology-management/40721

https://oxfordreference.com 


\section{Annex 1}

\section{Regarding Methodology. A Note}

Displaying the paper' Methodological scaffold-identified as a multimethod design (Judd, Smith, \& Kiddler, 1991) —in an Annex format, is an idea that rise from the interest to endow continuity to the structural focus of research analysis providing to this specific process theme a space of its own, with the deserved light for its careful complex net craft description, the description of the basics of the diversity of techniques used accordingly to each data-information operational requisite, and to explain the combination of presentation resources used to express visually their connections and interactions as means to offer insights into the research interest. This introduction strongly supports the idea of an ongoing complex process-oriented thematic research-operational-work as in... How is MOT Nomological Net configured? interplaying with an established content-articulation mental process of analysis and synthesis, as in... How is MOT Nomological Net Structure configured? clearly posed in the construct's internal composition dimension, conducted at the same time to attain the stated objective of interest. The core challenge of a research project of the present' kind seems to be found in the immersion journey into the variety of related ideas that lace the backbone of its own foundation whereas reveal the presence of a Complex Systems environment as is configured by a number of components which interact non-linearly whose linkages between, among, and within them fosters the complexity of the system (Byrne \& Callahan, 2013).

To get engaged in such an endeavor certainly relies on the researcher' interest, persistence and boldness, sufficient enough as to frame the works under the Why-Not Approach that is identified at the very first moment of the conception of the idea by the decision to consider the subject of attention in its formal language expression as is Management of Technology built upon an action transitive/verb that takes an operation-management, referring to direct/be in charge of/control/handle a situation-linked by a possession type simple prepositionof - to anaction subject/recipient-technology - that leads to the mental representation of the focused application of managerial activities over technology as a tangible/intangible resource representing a capital investment. If the following decision is in the Lets' Do It realm, the reality is touched by a research-formattedmind posing an operational process type of question: How to do it?, in the context of a theoretical-content-articulation type of research question focused in... is MOT Nomological Net Structure configured? positioned in the construct's internal composition dimension.

In this section is described, and briefly explained, the complexity of the rich methodological platform supporting the operational processes and activities conducted to handle the array of analysis methods and data collection techniques used for materials gathering, retrieval, selection, organization, analysis and interpretation conducted under a combination of deductive perspective for the analysis that turns into the inductive perspective as the net assemblage develops 
along a mental process identified as synthesis. Using a composite of processmapping-techniques to represent their interventions/use along the operational work, results in this matter feature 1) a General Methodological Process Diagram and 2) an operational Methodology' Map, integrated to the research' text in the Methodological Approach segment as means to deploy in a condensed manner the complex Methodological scaffold applied to face the requirements of this study' RQ... How is MOT Nomological Net Structure configured?

\section{1) Framing the Research}

a) Paradigm Set. Amongst the methodological constituents of this study, the paradigm setting is considered to be of extreme interest to establish the course of action of the entire research works. The view under which is positioned the problem of interest for analysis is determined at early design stage in order to benefit internal consistency through setting theoretic boundaries to the operational work. This is referred to as the analytical paradigm framing of the problem to be addressed. In this paper, the segment describing The Construct Theoretical Milieu supports the problem' analysis under the broad frame of the Economic Paradigm as sustained by the view of technology as a firm resource-operating as capital investment leveraged by management techniques with the purpose to benefit competitiveness and/or productivity-that impact economic variables at aggregate level. The paper' treatment of the Technology Landscape, is clear enough to fully understand the evolution of the theoretical thought involved with the perceived technology benefits for aggregate level of an Economy-macroeconomic view-as well as for Industry and Firm level known as the microeconomic view in which the Management principles became visible. At this point rises the importance to remark the coexistence and complementary interplay of those two perspectives as a distinctive feature to bring into account when Management of Technology meaning is involved, as it bears significance to how the Research Question is formulated.

b) Method \& Techniques. Being consistent with the extended notion of examining the past to understand the present events (Foucault, 1969), here the detailed operational process to undertake the research' framing step is based on an extensive/intensive literature review for materials selection as input for the indepth analysis of texts-involved in the research interest' boundaries-carried out following a Constructivism perspective attempting by document review...to make sense of or interpret the meanings that the texts bring by means of the search of a pattern embedded in the data source (Creswell, 2013)... With this purpose on mind, to address the paradigm setting stage of the study is considered to introduce, as suitable methodological device for documented information treatment, the historical perspective recognized by being used to examine business practices' origins, organizational structures, strategies and entrepreneurial characteristics widely published in specialized Journals, as exemplified in papers looking into the use of archival materials in business studies (Chandler, 1962; Galambos, 1970; Jones \& Khanna, 2006; Wilson \& Toms, 2008; Decker, 
2013).

Implementing this perspective, initial text review in this research follows a three stages continuum that starts by focusing the I) each main constructs'-technology and management-historiography collection upon which take on the materials' search operations that leads to constitute the basic source-net compiled to be examined in-depth to produce a fitting basic materials selection to II) input the analysis performed by the history review method which covers three steps that begin with: 1) documentation considered as a collective of materials identification/information compilation from published books, papers, articles, newspapers and documents of the kind-either as primary or secondary sources-followed by 2) text analysis and narrow selection that supports topics and subtopics identification to configure thematic arrangements that enable further organization and 3) information' interpretation (Good \& Scates, 1954); the continuum' stage III) consists in an iterative process applied to sources revision and analysis to extend/focus/verify/confirm either sources collection and information content. The iterative use of the sources is reflected in the citations included in the content of the resulting text.

The stages and steps of this revision process are operational activities carried out for materials' organization such as information identification, retrieval, assembly and meaning within the subject of interest. Justified in terms of the research' internal logic pursue, thematic arrangements of the information to be handled are made upon the basis of preserving the context of sources of different discipline origin by creating separate groups of knowledge under the thematic criteria, adopting the view from the provenance principle of the archival research field, regarded to be appropriate as here information is collected with the purpose of examination from sources in text already existing (Pearce-Moses, 2005). The use of the method at this stage lead to introduce into the analysis interesting value-added findings such as Tarde's (1895) contributions to innovation and imitation theory, Good and Scates (1954) detailed guidance into historic method, and to the early appearance of the Management and Technology notion as used by Woodward in 1958.

\section{2) Setting the Research Nature}

Being the foci of interest identified to be in the meaning dimension of the quest of knowledge, awareness rises for a research interest' nature related to a qualitative analytical approach, free from hypothesis stated or preconceptions determined, without measures involved, aiming to describe rather than explain the phenomena (Husserl, 2001), recognized in Weber' (1921/1978) description of Qualitative Research as an interpretative science (Denzin \& Lincoln, 2003). Framed on these characteristics, the research question is recognized to be of the How? type revealing the exploratory character of the study set under the Qualitative Research (QR) approach.

From here the research moves into a next level of operational work focused on the selection of the qualitative analytical approach type that match up with the 
stated Research Question being the one that tie in with the Grounded Theory approach as studies the interaction involving many theories/individuals looking to develop a theory grounded in dataof history, documents and text-literature sources being for this reason considered to be best suited to generate a theory illustrated by a figure (Creswell, 2013), which here turns to be the MOT construct' Nomological Net. A word of caution came out to benefit clarity regarding the differences between the selected approach type of QR and the phenomenology approach, focused on the meaning things have in a lived experience-being its fundamental goal to describe the nature of the phenomenon of interest (Creswell, 2013). This is considered to be a required notation as the two ideas seem to be related one to another (understand the meaning) as polar opposites upon the basis of their type of source (registered-data vs. subjective experience-data) and each one' defined purpose (develop a theory vs. describe the nature of a given phenomenon). Differences among the type of Qualitative research approaches are detailed in Figure A.

\section{3) The Grounded Theory Analytical Approach}

The information-processing operations implies initial activities to be performed with the purpose of information-source selection as basic input for the compilation required to configure an information (as in data) platform supporting either the paradigm selection, as the identification of the components to be engaged in the Grounded Theory Approach procedures (GT) required for further distinction of the MOT Nomological Net components. The information-source base collected is the input to be used in the stage of information-processing whose purpose is focused on key ideas extraction, and their correspondent organization

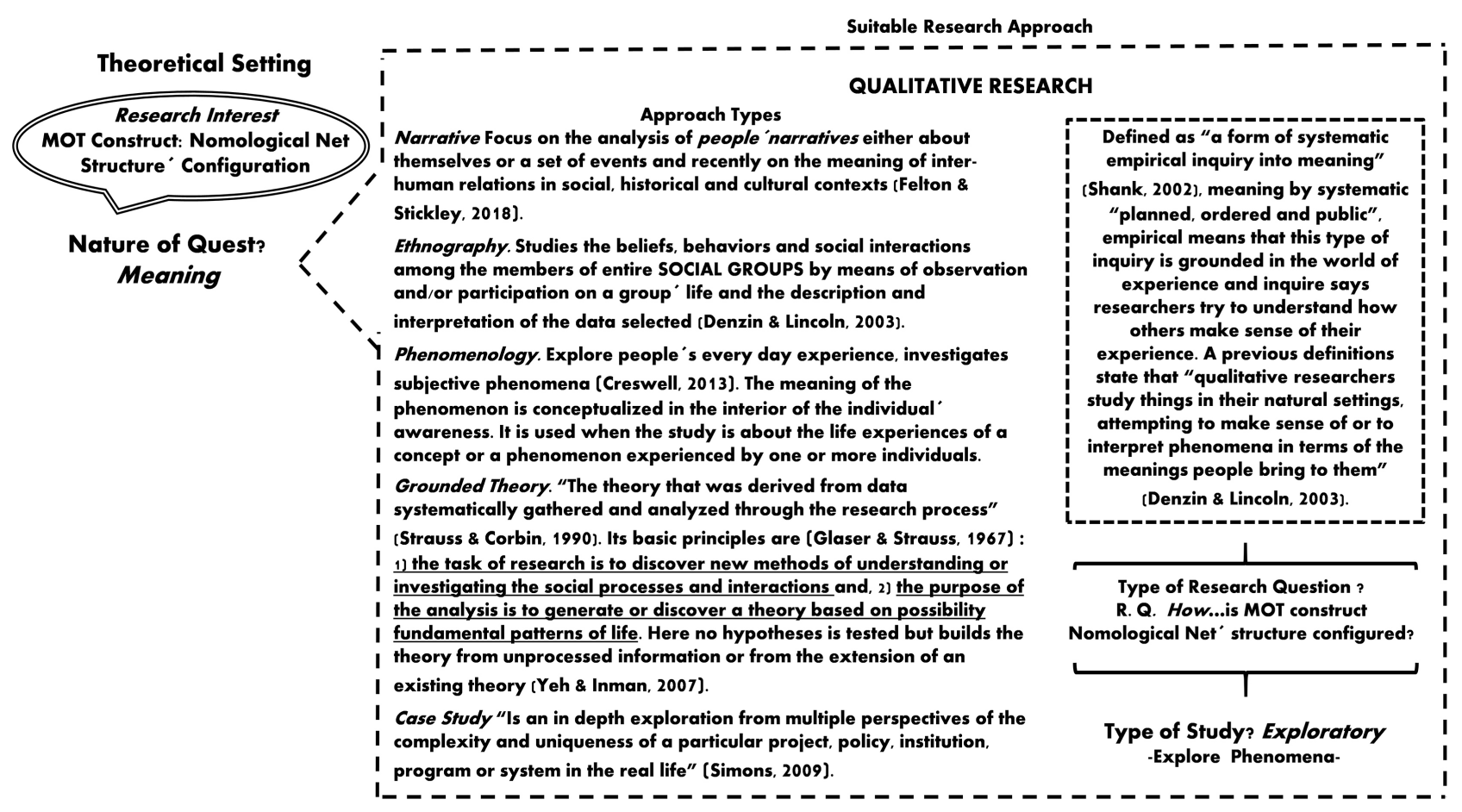

Figure A. Theoretical setting. Suitable research approach. Selected qualitative research approach type. 
and categorization. Information processing stage is conducted by using the GT three steps sequence (Glaser \& Strauss, 1967) applied basically to a) identify concepts of interest (open coding); b) identify relationships among concepts (axial coding); and c) select a core concept for analysis (selective coding) to form an explanatory theory, which in this research refers to identify how MOT construct' Nomological Net structure is configured. In the GT approach the term Theoretical Coding refers to an analytical action useful to conceptualize how categories and codes generated from information/data relate to each other, guiding the process of organization into types of families of theoretical codes that relate to each other establishing theory (Glaser \& Strauss, 1967).

a) Information Processing. Identification/Organization/Categorization. Coding. Applying the GT coding sequence, the retrieved information-processing procedure set in motion a chain of activities for operational work starting with carrying out the open coding technique-list codes either by word or by line as the concepts of interest appear from the text revision-conducted following (Strauss \& Corbin, 1990) criteria to form emergent codes based on... conceptually similar events/actions/interactions... These authors suggest that... the research process itself guides the researcher... (Strauss \& Corbin, 1990). At this point is considered the importance to underline that the activity of the coding phase is based on an inductive reasoning approach. To benefit the identification of the emergent concepts' range of influence, in this study the register criteria determined for information extraction is by text lines listed by source for further thematic organization and conceptual categorization. The resulting conceptually similar emergent codes (selective coding) are grouped as the Technology-Concepts (TC) and the Managerial-Concepts (MC) while the similar interactions identified are labeled as the Management-of-Technology-Concepts (MTC). The set of components identified for the Technology Concept (economic, production, resource, use \& usage and assets view), applied for the construct' NN articulation is an example at point.

The first coding stage termed open coding, involves an intense and iterative process of text lines selection, retrieval, listing, organization by reference ID, extraction from the lines basic list, and revision to refine, reorder, regroup or change categories until a sense of saturation is identified. Moving into the axial coding phase, works are focused on gaining accuracy by determining Categories' subordinates or grouping subcategories defined upon each concept' key features and in organizing their interactions into theoretical categories that configurate relations that lead to theory (Strauss \& Corbin, 1990). Setting these ideas at the Technology' Construct example, action refers to how at a given point of the research' operationalization process, Technology-related concepts are grouped in seven subcategories derived from characteristics related to criteria by area of influence, significance and form of observable manifestation. Covering the third or selective coding stage in this example, subcategories were organized around five central or explanatory concepts considered to be as the core building blocks of 
the Technology construct conceived under the Economic Paradigm. Along the operational process applied for materials' grouping and summarization, the working scheme is based on the use of text line, as well as in the connection existing between the analysis and interpretation of the coding process' results, and the text being developed, taking the attention into how here the Technology dimension concepts are linked configuring an internal net that gives theoretical density to the construct, as is need to be introduced-articulated-presented as content of the segment referred to as the construct' theoretical milieu.

b) Nomological Net Assemblage. With clear understanding that works on Nomological Net configuration are set at the synthesis mental process domain, from which an outcome of new and different nature is expected to be created upon the basis of a supportive analytical process, the methodological scaffold built in consistency to the Research Question requirements... How is MOT Nomological Net Structure configured? is completed by the implementation of the actions for the assemblage of the theoretical components into a visible structure-represented by a diagram-in which the MOT construct is implanted.

The concept of Nomological Net was introduced as means to assess construct validity in the context of psychological tests following a reasoning that to... "make clear what something is" means to set for the laws in which it occurs (Cronbach \& Meehl, 1955)... Thus, from Greek nomos a law + logos word, discourse or reason + Latin icalis of, relating to, or resembling (https://oxfordreference.com/), as in a form of definition Crombach \& Meehl (1955) declare that...the interlocking system of laws which constitute a theory are referred to as nomological network). The idea extended to the Social Sciences Research environment as... defining constructs its theoretical, abstract meaning, in conditions of other theoretically related construct (Judd, Smith, \& Kiddler, 1991). The basic principle of this notion is that to be scientifically admissible, a necessary condition to fulfill is that the construct is implanted in a nomological net. Thus, with the conviction that a map for understanding MOT construct' theoretical piece is a) an essential requirement to move forward in theory building, and b) a basic foundation to support decisions in regard to operational definitions' decisions, in this research supported by the rigorous chain of inferences built-in along the previous analytical process, the NN concept is applied as a tactical procedure to activate the Management of Technology construct' Nomological Net assemblage process, by following the established NN laws applied for such a purpose as the rules that frame the technical work.

Being established the course for the assemblage works, the process starts framed on the application of the NN law/rule in regard to... may relate different theoretical constructs to one another... which implies to define how the differentiated space for each of the main constructs involved is to be represented. Being MOT' construct circumscribed to a two parents construct' linkage, a plain boxes figure is selected as suitable visual representation device to establish differences among the convergent main constructs of interest and the linkages 
among them. The boxes figure selection proves useful to deploy as well each main construct' components cluster contained on the bounded space, as it is a necessary input to cover $\mathrm{NN}$ law referred to... relate observable properties to each other... in which the parent management and technology constructs' components as individual threads are linked creating patterns of relations-fostering its modular and flexibility attributes-into the MOT' theoretical structure. Applied in consistent alignment to the Research Question requirements, the procedural order followed to this point reveals as crucial to anchor the appearance of MOT as the new derived single unit-differentiated-independent construct in which the next procedural step takes place.

Recognized as an observable consequence of the parent constructs content' links working as two building blocks, MOT construct is represented, in the NN diagram configuration in its own boxed-space with its correspondent components' cluster configured by the parent constructs threads' interweaved-linkage from where the MOT' structural functions set emerge, each of them involving its specific blue prints. In consequence, the next procedural step is positioned in MOT' construct territory. Being the interest... to relate theoretical constructs to observables... the $\mathrm{NN}$ configuration gains complexity as these works implies both to relate MOT theoretical construct to observables, as well as its individual theoretical components to observables, creating a two layered operational environment. It is through this step that MOT theoretical framework is linked to its pragmatic framework represented by a box containing a list of observable Management of Technology Structural Functions outputs, completed by a list of given observable-in-action MOT techniques, procedures and methodologies bounded by a box set at the bottom of the diagram in direct reference to the visible and tangible connection between the theoretical and the actionable practical nature of the Management of Technology term.

Pushing the boundaries appointed by the Research Question nature, NN quality assessment venue is broadly outlined through its application into an operational MOT scenario following the Trochim and Land (2006) research design' quality criteria suggested by Stegmann (2014) for NN evaluation purposes in terms of five conditions: 1) theory grounded, due that for each of its linkages a directional effect is justifiable by a theory, as is visible in Diagram 6; 2) situational, for being the two main constructs and their linkage' outcome involved in the particular context in which they perform; 3) feasible, since this NN is mainly structured by theoretical components that represent actionable processes, it is feasible to manage specific groups of theoretical components as illustrated by the modular attribute identified; 4) redundant, as any specific process can be activated several times-due to the flexibility attribute-either running at their own pace at any time required by the MOT activity and at in any mode of alignment, synchronization, intermittence, continuous flow and in any type of role as enabler, support, complement, key-central axis, and so forth, 5) efficient, NN usefulness is identified by its role as MOT scattered component' articulation figure 
centering the construct into a unique meaning environment, as well as for its flexibility to be used as a roadmap in which MOT structural functions and correspondent techniques, methodologies and procedures are allocated.

The workable venue of MOT' Nomological Net was applied following a single fiber selecting for such purpose the Logistics Function as its technology platform integrates physical material movement base technology and an information flows transmission enabler technology (technology resources), being the complexity of the application raised by introducing SCM as the operational environment to integrate the set of electronic operations \& processes, ID standards and electronic messages in due course. In this setting a strong technology knowledge base is recognized as a crucial component of the technology platform. The function's complexity lead to fundamental operational decisions in regard to outsourcing either the complete function (a third partner logistics mode), a partial detachment mode (services supplier for an specific logistics operation), a combined management/operational mode (controlling logistics management decisions/operating through a services supplier platform), by the full control of the function assuming the investment requirements and operational risks (Logistics function ownership mode) to make reference to the most common operational decisions. An outline of this illustration is presented in Annex 2.

\section{Annex 2}

\section{Management of Technology Construct' NN in Action}

Framing MOT' on field-activities in its NN theoretical base is a paramount step for the research works' closure, being selected for doing the Logistics Function identified as a complex two-layered technology-multi-technical-operational environment. Being the results of this NN usage kept out of this paper' content because of length reasons, an outline is introduced to briefly illustrate the visible side of a theoretical meaning. Consistent to its strategic nature, at firm level Management of Technology permeates the normative-structural corpus, both at macrolevel (International Legislation, Norms, Regulations and industry Standards) and Microlevel (Inter-Functional) as illustrated in the follow-up of the selected Logistics Function' fiber working simultaneously_in conditions of alignment, synchronization, timing, safety, collaboration and cooperation-with both operational physical flows movement (warehousing management \& control technology, scanning technology picking and assortment equipment, package technology, transport equipment scheduling, transportation-routing definition, traffic documentation and legal requirements among others) and information flows management (IT/Information Systems/Product ID standardized codes/Scanning technology/Electronic Messages/ and a wide array of related software programs) that configure the Logistics' Technology Platform set in motion through vertical and horizontal interaction with other organizational functions as follows:

Vertical Consistency

1) Strategic Function Links to a Strategic Resource. Firm's Strategic Business 
Plan, (Business strategies strategic objectives, business goals, business Key Performance Indicators, Investment Plan \& Operational Budget program, Strategic Projects assessment) set the course for the Logistics Function' alignment to a) the defined organization' Strategic Objectives and b) the inter-functional Logistics-related activities requirements. Logistics function' alignment is mirrored in a Strategic Technology Plan and a derived Logistics Technology Plan/Program. The Logistics Function' plays a strategic role within Business strategies either as: enabler, support, complementary, fundamental, intertwined, integrated to business partners operations, shared, either as own or as fully/partially outsourced function. The Logistics Plan is developed, Logistics Projects are defined to fill-in existing gaps to face strategy' requirements. Logistics' technology platform - for physical and information flows management-is updated, enhanced, innovate, built up, managed by third party, etc. (equipment, machinery, IT infrastructure \& systems platform, facilities, technical skills etc.), decisions regarding outsourcing emerge. Technology Audit and Technology Readiness Assessment are conducted to identify gaps.

2) Logistics strategy definition (global, regional, local = internal policy). Logistics Function operations' consistent-derived programs (suppliers management, inventory management, traffic management, transport modes management, packaging \& assortment operations, distribution program: planning, scheduling, delivery), Logistics Projects: new and under development for instance material' storage facilities automatization or a distribution center figure to be add to existing facilities or the implications of a new electronic business model for the firm's Logistics operations, Logistics investment plan, Logistics operational budget program, Logistics E-Platform management, Logistics operations-programsprojects control and assessment, etc. Data Bases configuration as Logistics Systems platform input. Logistics Technology Audit implementation, Logistics Technology Portfolio configuration, and selection-valuation-implementation of any given of the Logistics solutions fitting the business and technical context of the industry in which a company competes.

\section{Horizontal Consistency}

Logistics key attribute is its' performance as across management function interacting, setting common goals and or objectives, either by providing/operating/ managing the physical movement of materials and goods, as to enabling its' operations by means of a specific information technology platform running as an independent but integrated electronic systems net that links the Logistics operations with manufacturing/operations (warehouse, suppliers and in-house/vendor inventory management for instance) marketing (demand planning, assortment operations, delivery scheduling on the firm's distribution channels, etc.) and other managerial functions-internal/external-by connection to ERP systems finance, budget program, procurement and HRM modules among others. Logistics organizational structure' models are found in different shapes and forms from an operational unit, to several units attached to other operations (warehouse man- 
agement for manufacturing, shipment, materials, finished products inventory, and the sort), to a full consolidated division as in major global-apparel-firms or operated by a third party or partially/fully outsourced. Works at strategic, tactical and operational levels. The organizational structure model shapes the kind of technology platform articulation as well as the range of logistics-technology investment decisions' priorities. This scenario gains complexity and extension when the firm operated as within the context of Supply Management business partnership as the information flow may run as well from ERP to ERP individual, shared or common platforms. 